\section{AN INITIAL LABORATORY EVALUATION OF A SINGLE SOLUTION CIRCUIT CYCLE FOR USE WITH NONAZEOTROPIC REFRIGERANTS}

\section{Martin Buschmeier}

Universitaet Hannover

West Germany

\section{William Mulroy David Didion}

\section{U.S. DEPARTMENT OF COMMERCE Natlonal Institute of Standards and Technology Natlonal Engineering Laboratory Center for Buliding Tochnology Bullding Environment Division Galthersburg, MD 20899}

\section{Sponsored By:}

Offlce of Bulldings and Community Systems U.S. Department of Energy through Oak RIdge Natlonal Laboratory under contract DE-AC05-840R21400 with Martin Marletta Energy Systems, Inc. 



\title{
AN INITIAL LABORATORY EVALUATION OF A SINGLE SOLUTION CIRCUIT CYCLE FOR USE WITH NONAZEOTROPIC REFRIGERANTS
}

\section{Martin Buschmeier}

\author{
Universitaet Hannover \\ West Germany

\section{William Mulroy David Didion}

U.S. DEPARTMENT OF COMMERCE National Institute of Standards and Technology

Natlonal Englneering Laboratory Center for Bulliding Technology Buliding Environment Division Galthersburg, MD 20899

Sponsored By:

Office of Bulidings and Community Systems U.S. Department of Energy through Oak Ridge National Laboratory under contract DE-AC05-840R21400 with Martin Marletta Energy Systems, Inc.

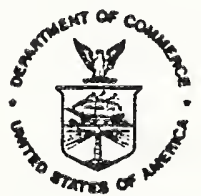




\section{Executive Summary}

Tests were conducted at the National Institute of Standards and Technology (NIST, formerly the National Bureau of Standards) to evaluate a single solution circuit cycle for use with nonazeotropic refrigerant mixtures. These tests were performed on the NIST breadboard heat pump, an easily reconfigured, heavily instrumented, water-to-water heat pump system. For this cycle a variable speed, liquid refrigerant (solution circuit) pump was added in parallel to the normal refrigerant compressor.

The addition of the solution pump allows the cycle to operate with heavy flooding into an accumulator instead of complete evaporation resulting in a reduction of the available temperature glide of the nonazeotropic refrigerant depending on the pump speed. This allows matching of the refrigerant glide to that of the heat source, thus theoretically increasing cycle efficiency. The flooding refrigerant is separated in the accumulator; the liquid and vapor are returned to the condenser by the solution pump and the compressor, respectively.

The application studied in this report was one in which glide is adjusted to match the heat source as discussed above and, simultaneously, the refrigerant composition is shifted to allow load matching and elimination of the cycling losses. With a normal vapor compression cycle it is impossible to do both simultaneously because glide in this use is a function of composition.

Since the single solution circuit cycle can only reduce, not increase, glide, a refrigerant mixture of very high glide, R22/R11, was chosen for 
this study to allow glide matching over as wide a composition range as possible.

The ability of the single solution circuit to match glides was demonstrated. Because of the nonlinearity of two-phase enthalpy as a function of temperature of the high glide refrigerant mixture chosen, the potential efficiency improvement over a pure refrigerant was not realized. The maximum efficiency improvement over pure R22 was only 198 as compared to a $32 \%$ improvement measured in a previous study at the same conditions [3] with a more linear refrigerant mixture. This nonlinearity is inherent in high glide binary refrigerant mixtures. It is recommended that more linear mixtures be used for such applications in the future.

It was found that composition shifting to match reduced loads and thereby reduce cycling losses to the extent possible with the mixture R22/R11 is not an efficient control strategy. This was because at light loads the fixed compressor losses, due to friction, become a higher percentage of the total capacity. Composition shifting to increase capacity for low temperature heat pump operation remains highly recommended.

The single solution circuit cycle appears to be best suited to applications in which glide varies with load and in which the glide is relatively high at full load. Modulating capacity to match light loads would best be provided by conventional means (variable speed or cyclic compressor operation) instead of composition shifting. 


\section{Abstract}

Tests were conducted at the National Institute of Standards and Technology (formerly the National Bureau of Standards) to evaluate a single solution circuit cycle for use with nonazeotropic refrigerant mixtures. The single solution circuit cycle incorporates a liquid refrigerant pump in parallel with a compressor. This allows separate control of refrigerant composition to match load and of refrigerant temperature change (glide) in the two-phase region to match the heat source or sink temperature glide. Load matching by composition shifting to match light loads to the extent possible with the tested mixture (R22/R11) was found to be an inefficient air conditioning mode control strategy. Nonlinearity of enthalpy vs. temperature in the twophase region of the R22/R11 limited the efficiency gains possible by glide matching to a 198 improvement over pure R22. The cycle did function as intended, allowing glide matching over a wide composition change. It is felt that with a more linear refrigerant, substantial efficiency gains over the normal vapor compression cycle would be possible for applications in which the heat source and sink glides vary substantially with load.

Key words: air conditioning; capacity modulation; heat pumping; nonazeotropic refrigerants; refrigeration cycles; refrigerant mixtures; single solution circuit; vapor compression cycle 


\section{Acknowledgements}

The authors acknowledge the contributions of $\mathrm{Dr}$. Reinhard Radermacher for selecting the cycle used in this study as one showing promise, of Dr. Mark McLinden for information on refrigerant properties and explanation of their interaction with the cycle, of Maciej Chwalowski for the presented computer simulations, and of Dipl.-Ing. Juergen Pannock for assistance in completion of this study. 
Executive Summary ................. . iii

Abstract . . . . . . . . . . . . . . v

Acknowledgements ............... . . vi

Table of Contents................. . vii

List of Figures................ . . viii

1. Introduction ................ 1

2. Background ................ . . 4

3. Test Apparatus . . . . . . . . . . . 12

4. Test Procedure . . . . . . . . . . . . 14

5. Error Analysis . . . . . . . . . . . 16

6. Test Results . . . . . . . . . . . . . 18

6.1 Compressor Losses . . . . . . . . . . . . 18

6.2 Vapor Compression Cycle . . . . . . . . . . . 24

6.3 Single Solution Circuit Cycle . . . . . . . . 27

7. Discussion . . . . . . . . . . . . . 31

8. Conclusions . . . . . . . . . . . . . 33

9. Future Work . . . . . . . . . . . . . 33

10. References ............... . . 34

11. Appendix: Error Analysis Equations ........ 36 
Figure 1: Schematic drawing of the single solution circuit cycle. 2

Figure 2: Gliding temperature during phase change for a nonazeo- 4 tropic mixture.

Figure 3: Carnot and Lorenz cycle representations. 6

$\begin{array}{lll}\text { Figure 4: } & \text { Temperature glide versus composition. } & 8\end{array}$

$\begin{array}{llr}\text { Figure 5: Theoretical COP vs. composition. } & 8\end{array}$

Figure 6: Theoretical volumetric capacity vs. composition. 9

Figure 7: Theoretical COP vs. volumetric capacity. 9

Figure 8: Temperature vs. composition diagram comparison of single 11 solution circuit and vapor compression cycles.

Figure 9: Schematic drawing of the as-installed single solution 13 circuit cycle.

Figure 10: Relative errors in COP measurement. 18

Figure 11: Compressor mechanical loss. 19

Figure 12: Compressor efficiency vs. composition (experimental 19 data).

Figure 13: Compressor efficiency vs. composition (experimental data 21 corrected for mechanical losses).

Figure 14: Pressure-enthalpy representation of compressos mechanical 23 losses.

Figure 15: COP vs. composition for the vapor compression cycle (experimental data).

Figure 16: Comparison of computer simulation to experimental vapor compression cycle data.

Figure 17: Comparison of COP vs. composition for the single solution circuit cycle to that of the normal vapor compression cycle.

Figure 18: Evaporator temperature profiles for various solution pump 30 speeds.

Figure 19: Comparison of COP vs. capacity/revolution for the single 31 solution circuit cycle to that of the normal vapor compression cycle. 


\section{Introduction}

Two ways in which nonazeotropic refrigerant mixtures have been used to improve the efficiency of air conditioners and heat pumps are glide matching $[1,2,3]$ and composition shifting $[4,5]$. Glide matching improves cycle efficiency by matching the glide (temperature change in the two-phase region) of a nonazeotropic refrigerant mixture to the temperature change (glide) of a sensible heat source or sink fluid (such as air or brine) as it passes through the heat exchanger. Composition shifting changes the composition of the refrigerant by distillation resulting in a change in system capacity. For the application discussed in this report this should improve system efficiency by reducing cycling at low loads. In the case of heat pumps, composition shifting can be used to increase capacity and reduce the need for resistance heat at low heat source temperatures.

At a given pressure, there are only two compositions at which a binary nonazeotropic refrigerant mixture will have a specific glide. That is, it is not generally possible to use composition shifting to match load and simultaneously match the heat source or sink temperature glide. The single solution circuit cycle $[6,7]$ tested in this report was intended to overcome this difficulty by making it possible to adjust the glide at a given composition from near zero to the maximum possible for the mixture used.

The single solution circuit cycle is shown schematically in Figure 1 . It consists of a liquid pump in parallel with a normal compressor. Glide is reduced by allowing heavy flooding into an accumulator instead of allowing evaporation to proceed to saturation at the dew point temperature. The 
liquid and vapor components of the flooding refrigerant are separated in the accumulator and are pumped to the condenser by, respectively, a solution pump and compressor.

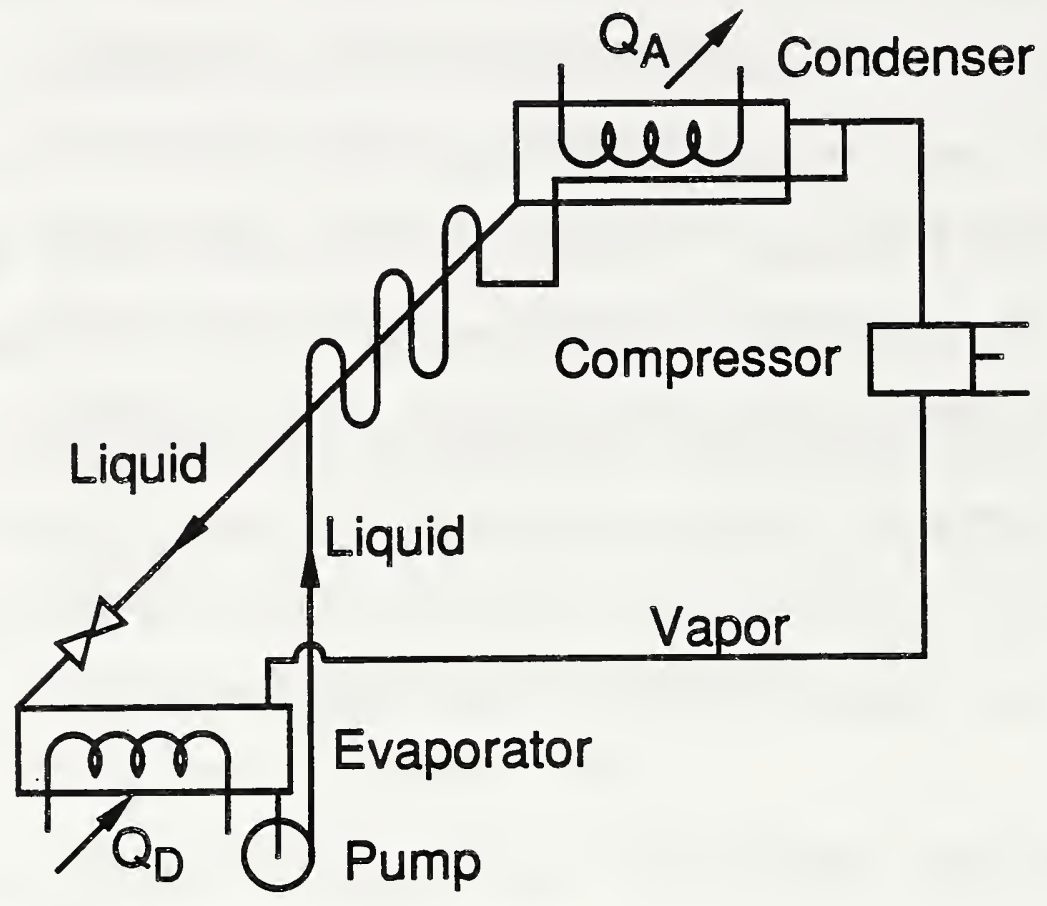

Figure 1: Schematic drawing of the single solution circuit cycle.

Since the single solution circuit cycle was intended to be used with composition shifting and is capable of reducing (but not increasing) glide it was felt that it should be used with a nonazeotropic refrigerant mixture of which the composition could easily be changed by distillation and which had a higher glide than would normally be desired. These characteristics are consistent. Mixtures of refrigerants which are far apart in boiling points are easily separated by distillation and have high glides. The mixture selected was of R22 (atmospheric saturation temperature of $-41.5^{\circ} \mathrm{F}$ ) and R11 (atmospheric saturation temperature of $74.5^{\circ} \mathrm{F}$ ). The maximum glide 
of this mixture at atmospheric pressure is approximately $68^{\circ} \mathrm{F}$.

The tests were conducted using the National Institute of Standards and Technology (NIST) breadboard heat pump. This is a heavily instrumented water-to-water heat pump with a dynamometer-driven open compressor. The tests were conducted at temperatures simulating air conditioning operation. Composition shifting was not obtained by hardware included in the cycle but was simulated by charging the system to a desired concentration.

In addition to the single solution circuit cycle, the effect of heat exchange between condensed refrigerant and evaporating refrigerant throughout the length of the evaporator on $\operatorname{COP}$ was also studied $[3,8]$.

It was found that the anticipated gain in low load efficiency by using composition shifting to achieve very low capacities could not be obtained because of compressor mechanical losses which become relatively high at low capacities. The high glide refrigerant that was chosen resulted in diminished glide matching gains (a 198 improvement over pure R22 was observed) as a result of nonlinearity of its enthalpy as a function of temperature in its two-phase region (in comparison to a 328 improvement previously observed [3] with another mixture). It is felt, however, that this cycle shows promise for applications in which glide varies with load when used with a more linear refrigerant mixture and with conventional part load control methods. 


\section{Background}

A phase (temperature vs. composition) diagram for a nonazeotropic mixture at a fixed pressure is shown in Figure 2. Following a condensation process, superheated vapor at point " $a$ " is cooled to the dew point "b", where it begins to condense. Throughout the two phase region, liquid and vapor compositions will differ. At a point " $c$ " in the two phase region these compositions, $\chi_{\ell}$ and $\chi_{\mathrm{v}}$, may be found by drawing an isotherm as shown. The refrigerant is completely condensed at the bubble point "d" and subcooled at point "e".

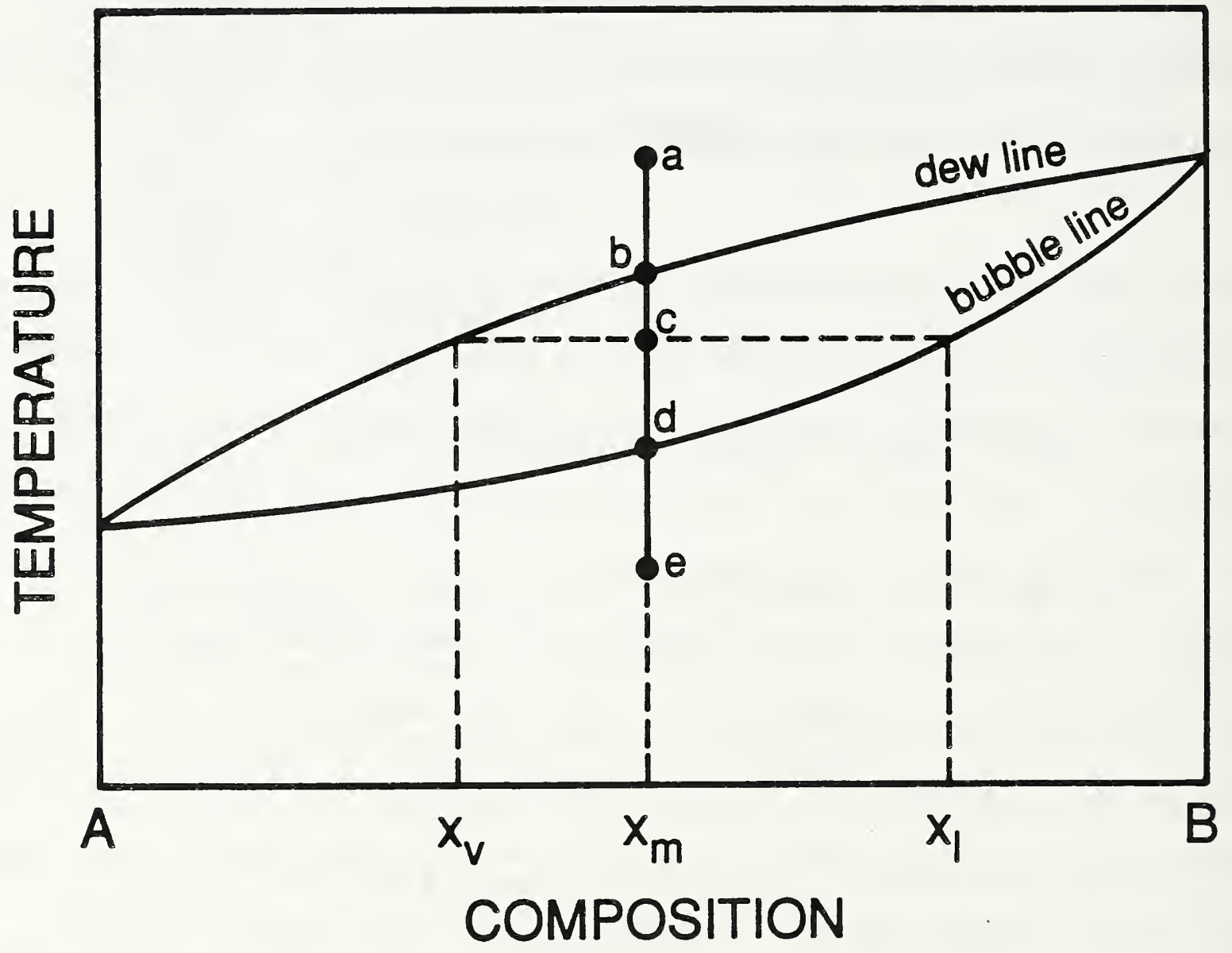

Figure 2: Gliding temperature during phase change for a nonazeotropic mixture. 
Composition shifting is achieved by taking advantage of the differing liquid and vapor compositions in the two-phase region. In the condensation example just given, the vapor in equilibrium with point " $d$ " is greatly enriched in the more volatile component. This could be drawn off, condensed, and stored resulting in enrichment of the refrigerant remaining in circulation in the system with the high boiling component. A shift in the opposite direction could be achieved by storing liquid refrigerant in an accumulator at the outlet of the evaporator (point " $b$ ").

The concept of glide matching is shown on temperature vs. entropy coordinates in Figure 3 for the case of infinitely large heat exchangers. A Carnot cycle, Figure 3a, consists of two isentropic processes and two isothermal heat exchanges. Isothermal fluids that could be used in an approximation of such a cycle would be those that do not change temperature in the two phase region such as steam, pure refrigerants, and azeotropic mixtures of refrigerants. The inefficiency of this cycle, when the heat source and sink are sensible fluids (these that change temperature with the addition or removal of heat) such as air or water, is indicated by the cross-hatched area.

In the Lorenz cycle, Figure $3 b$, it is assumed that the refrigerant is a sensible fluid such as a nonazeotropic refrigerant mixture. All heat exchanger inefficiency is eliminated when the refrigerant glides match the heat source and sink glides as shown by the absence of cross-hatched areas.

Actual nonazeotropic refrigerants are not perfectly linear in entropy (or enthalpy) as a function of temperature. Example, nonlinear refrigerants are 


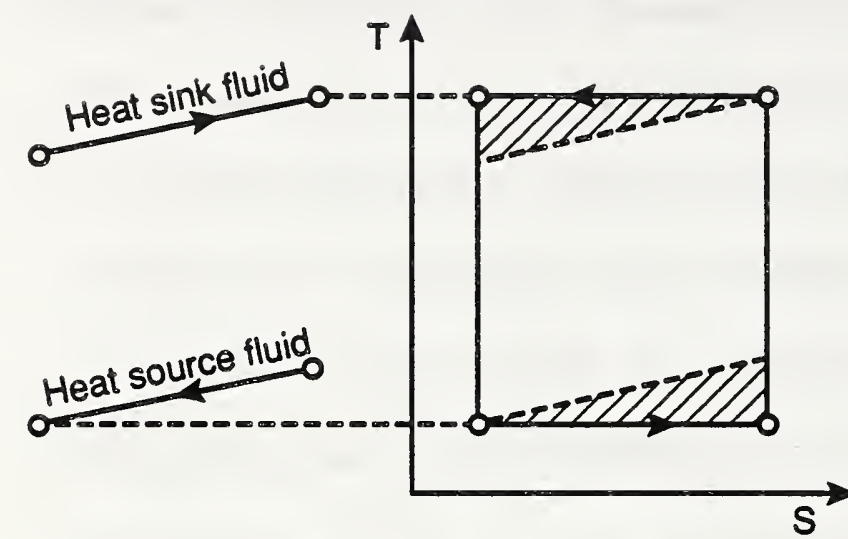

a) Carnot cycle

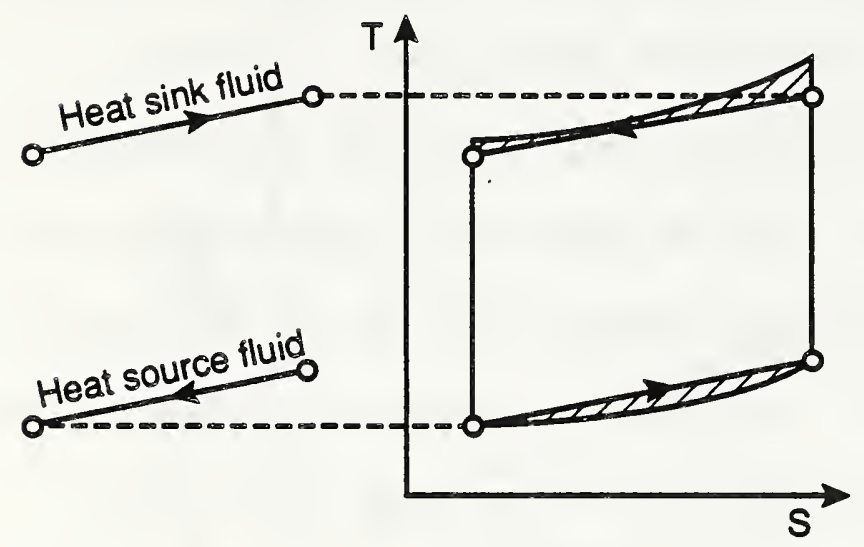

c) Concave nonlinear refrigerant

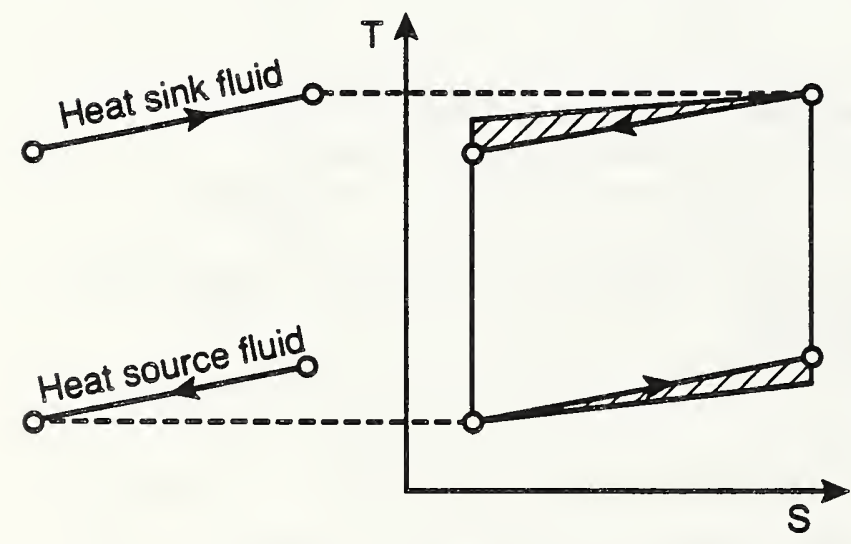

e) Undergliding refrigerant

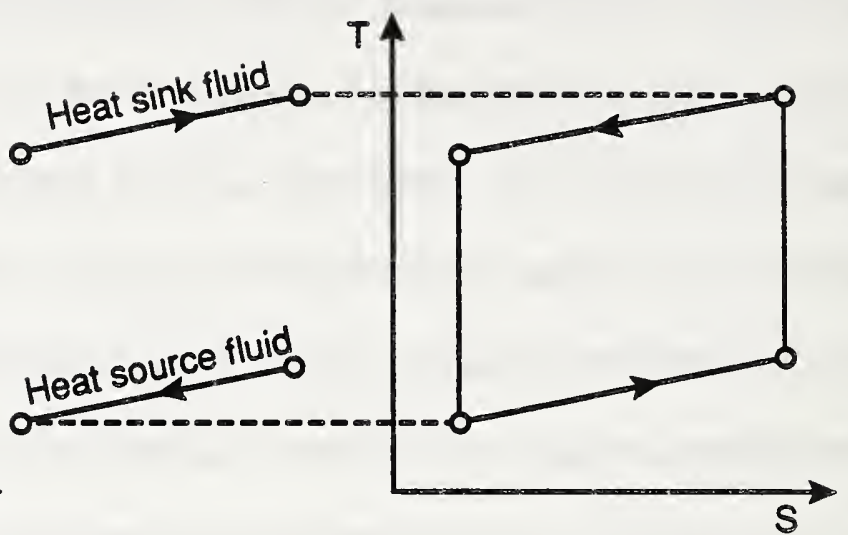

b) Lorenz cycle

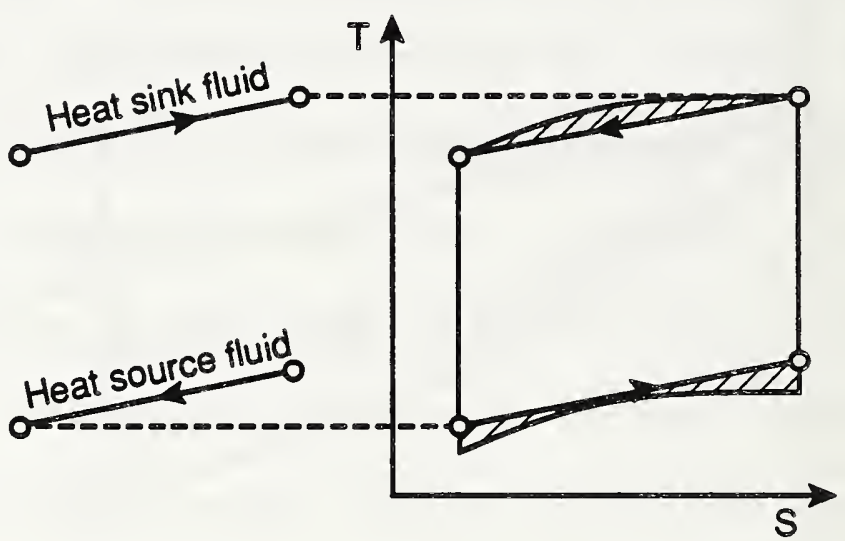

d) Convex nonlinear
refrigerant

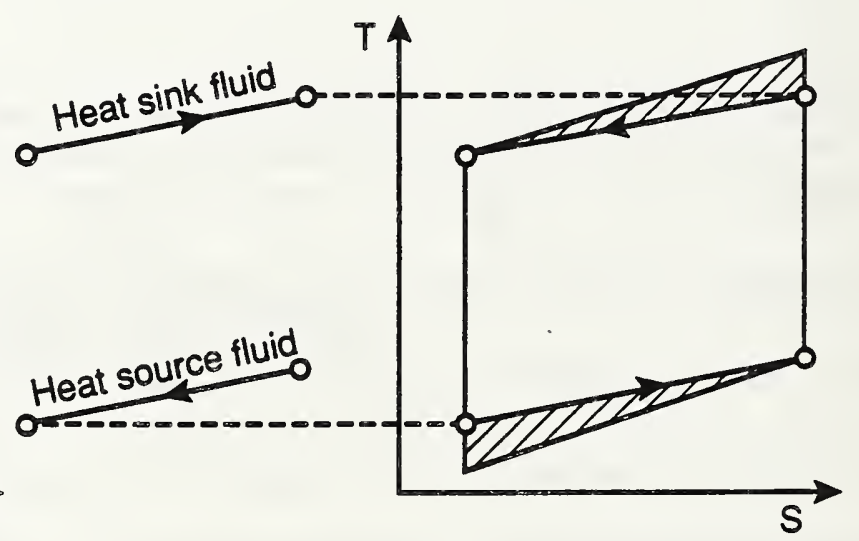

e) Overgliding refrigerant

Figure 3: Carnot and Lorenz cycle representations. 
shown in Figures $3 c$ and $3 d$. This nonlinearity introduces inefficiency as again represented by cross-hatching. A mixture in which the more volatile component is predominant will be concave with pinch points on the ends of the heat exchange process in the evaporator but within the condensing process, as shown in Figure 3c. A mixture in which the less volatile component is predominant will be convex with pinch points within the evaporator, and at the ends of the condenser, as shown in Figure 3d. Nonlinear refrigerant mixtures may have use in processes using nonlinear heat sources such as air dehumidification or ice-making applications.

Figures $3 e$ and $3 f$ indicate the inefficiencies and the location of the pinch points when using mixtures that have too little (undergliding) or too much (overgliding) glide. The overgliding case is of interest for this study as the base case before operation of the single solution circuit cycle's solution pump. The solution circuit can be used to reduce the glide so that matching occurs as given in Figure $3 \mathrm{~b}$.

From temperature-entropy considerations, glide matching can be seen to be paramount for highest theoretical efficiency. Glide is normally set by load requirements. As can be seen in Figure 2, a binary refrigerant will be able to match a specific glide less than its maximum at two compositions, one on each side of that composition producing the maximum glide. This is emphasized in Figure 4. Cycle efficiency (COP) is expected, therefore, to be at a maximum at the two concentrations where glide matching occurs, and less elsewhere as a result of either excessive or insufficient glide (Figure 5). 


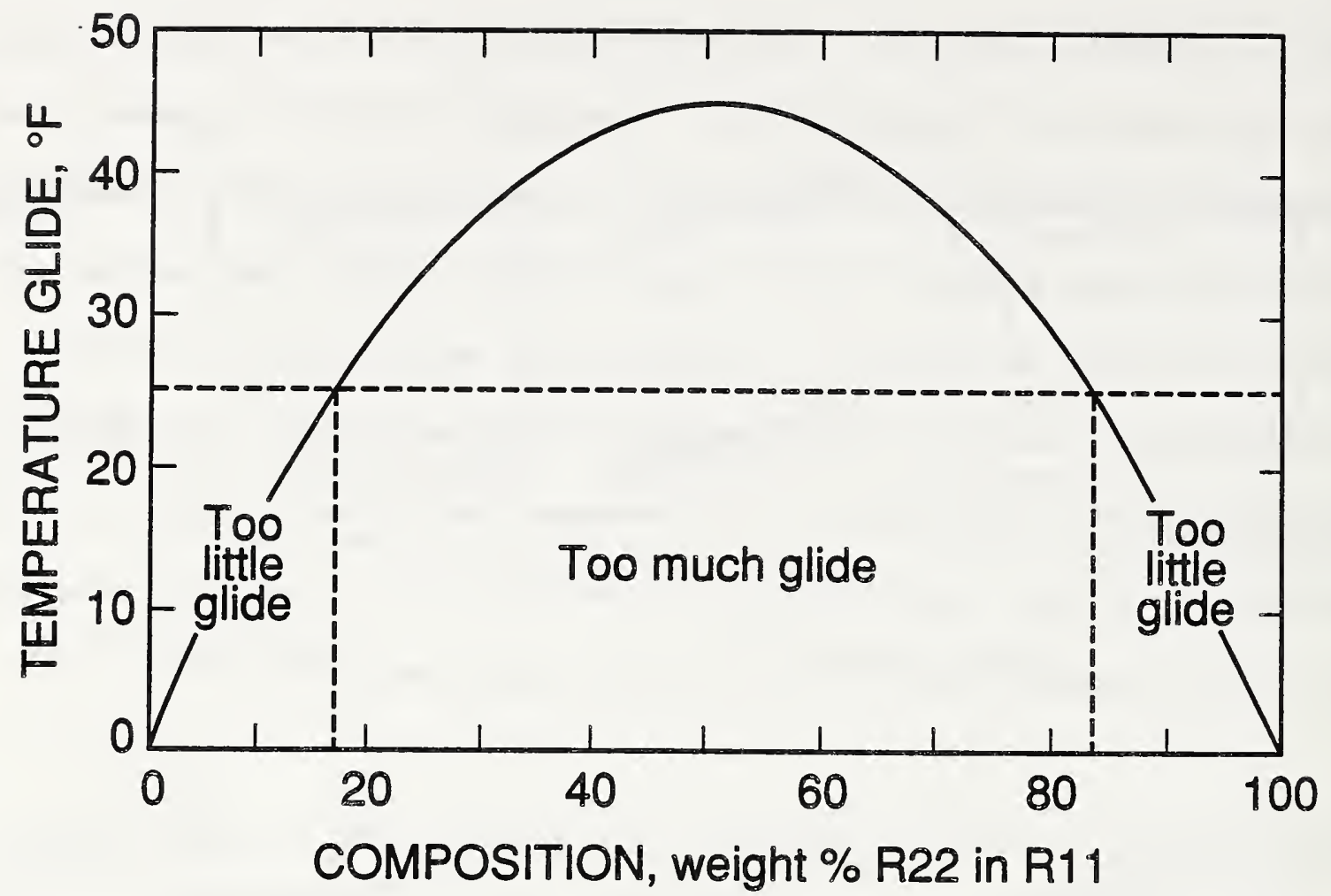

Figure 4: Temperature glide versus composition.

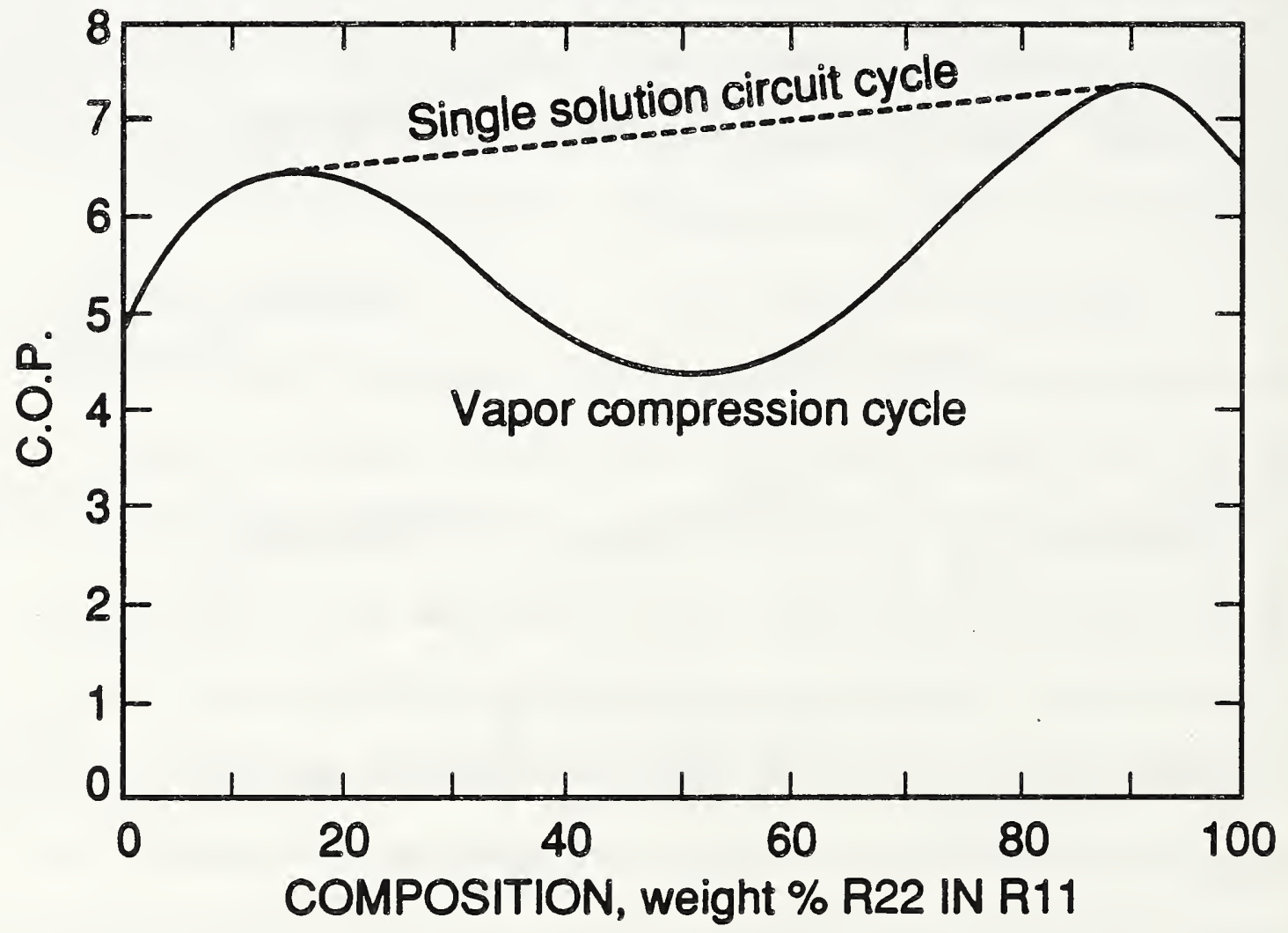

Figure 5: Theoretical COP vs. composition. 


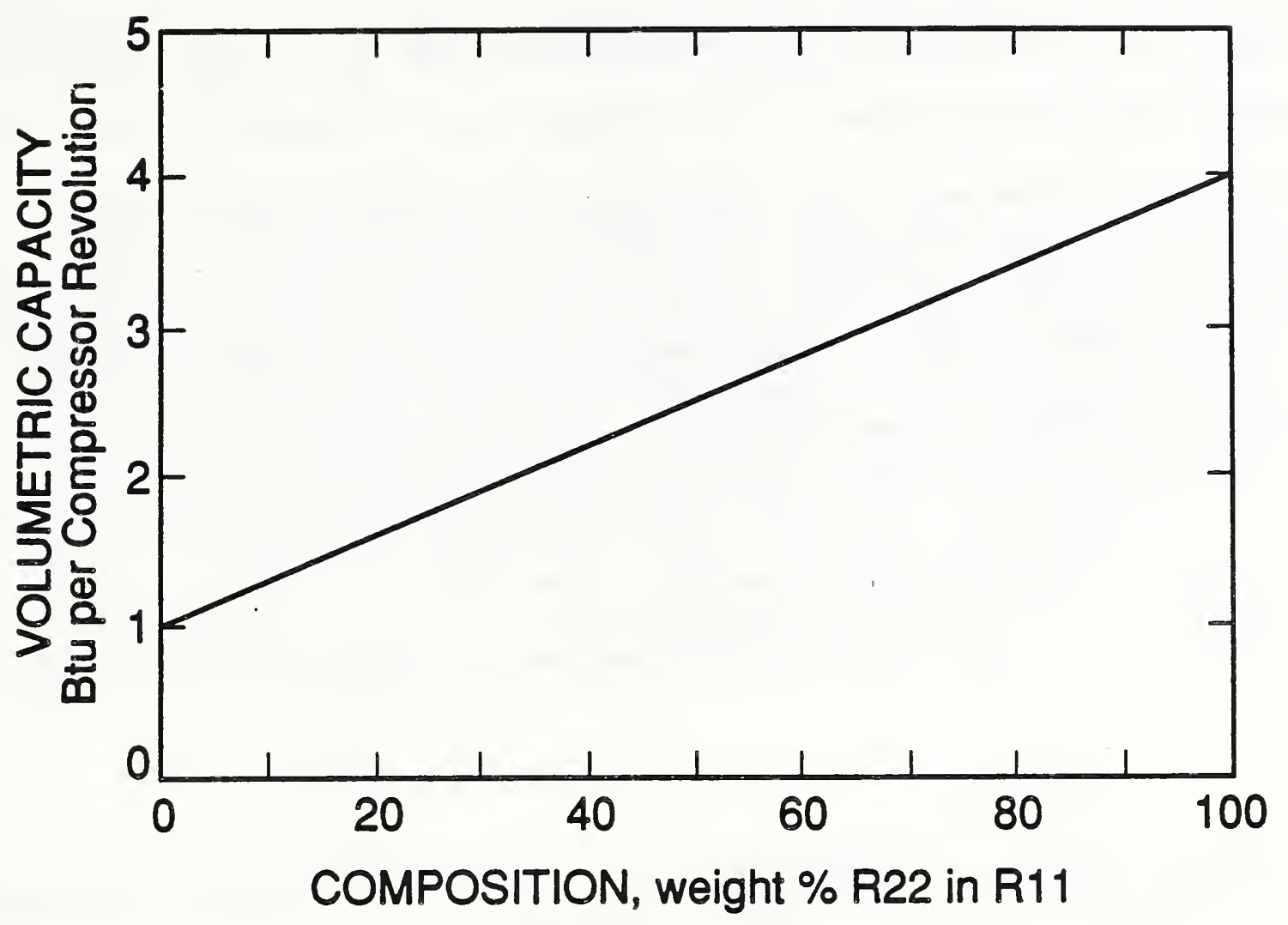

Figure 6: Theoretical volumetric capacity vs. composition.

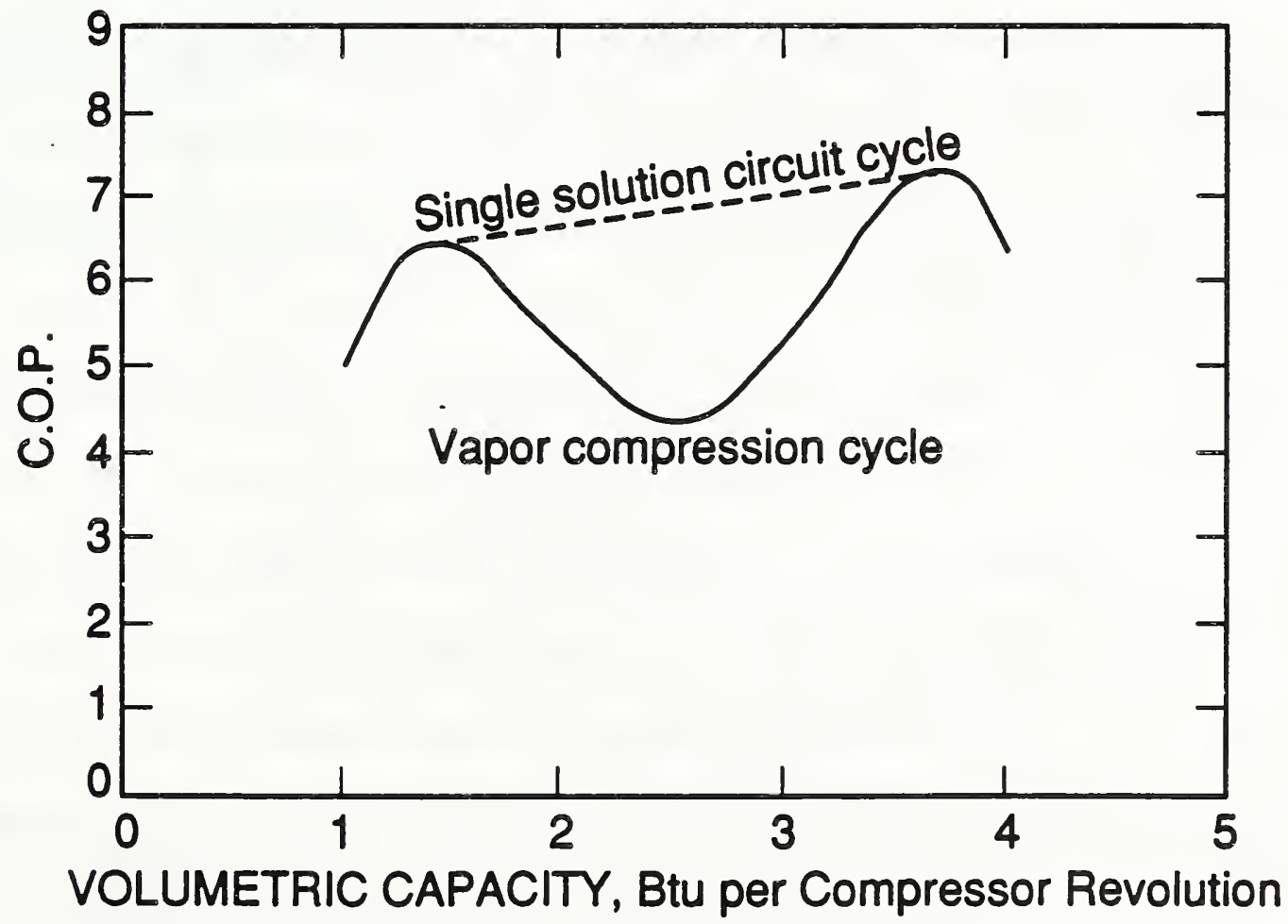

Figure 7: Theoretical COP vs. volumetric capacity. 
The single solution circuit cycle can provide glide matching in areas of intrinsic overgliding as shown by the dotted line in Figure 5. The volumetric capacity can be expected to vary substantially linearly from one pure component to the other as shown in Figure 6 . Figures 5 and 6 can be crossplotted to provide a curve of expected efficiency vs. volumetric capacity for load modulation in a constant heat source and sink temperature glide application (Figure 7). The drop in mid-range efficiency shown in Figure 7 (as in Figure 5) results from excessive glide and can be eliminated (as shown in Figures 5 and 7 by a dotted line) by use of the single solution circuit cycle.

As previously discussed, in this cycle the evaporation process is halted at the optimum temperature glide. The effect of partial evaporation and condensation when starting with an overgliding refrigerant mixture for the single solution circuit cycle is shown in Figure 8 . In the condenser of a conventional vapor compression cycle, refrigerant would enter as superheated vapor, point ${ }^{m} \mathrm{a}$ ", and be condensed at the bubble point, point ${ }^{\mathrm{C}} \mathrm{c}$, where a pinch point occurs (as shown in Figure $3 f$ ). In the single solution circuit cycle, two phase refrigerant will enter the condenser at point " $b$ " and the cycle will be otherwise the same. In the vapor compression cycle refrigerant will enter the evaporator flashing to point " $f$ " and will leave at the dew line, point "d". In this case, the pinch point is at the evaporator outlet point "d" as shown in Figure $3 f$. Therefore, the low quality refrigerant leaving the evaporator in the single solution circuit cycle will also be at the point ${ }^{n} \mathrm{~d}^{n}$ temperature when glide matching occurs. The entering condition in the single solution circuit cycle will be at point " $e^{n}$. The evaporator pressure 
will be higher for the single solution circuit cycle than for the normal vapus compression cycle.

An additional cycle modification studied in this project was heat exchange between the refrigerant leaving the condenser and the refrigerant in the evaporator in counterflow throughout the length of the evaporator $[3,8]$.

This liquid line subcooling decreases flashing entering the evaporator which results, for nonazeotropic mixtures, in a lower average evaporator temperature at the same pressure, or in the same evaporator temperature at a higher pressure (and hence, higher efficiency).

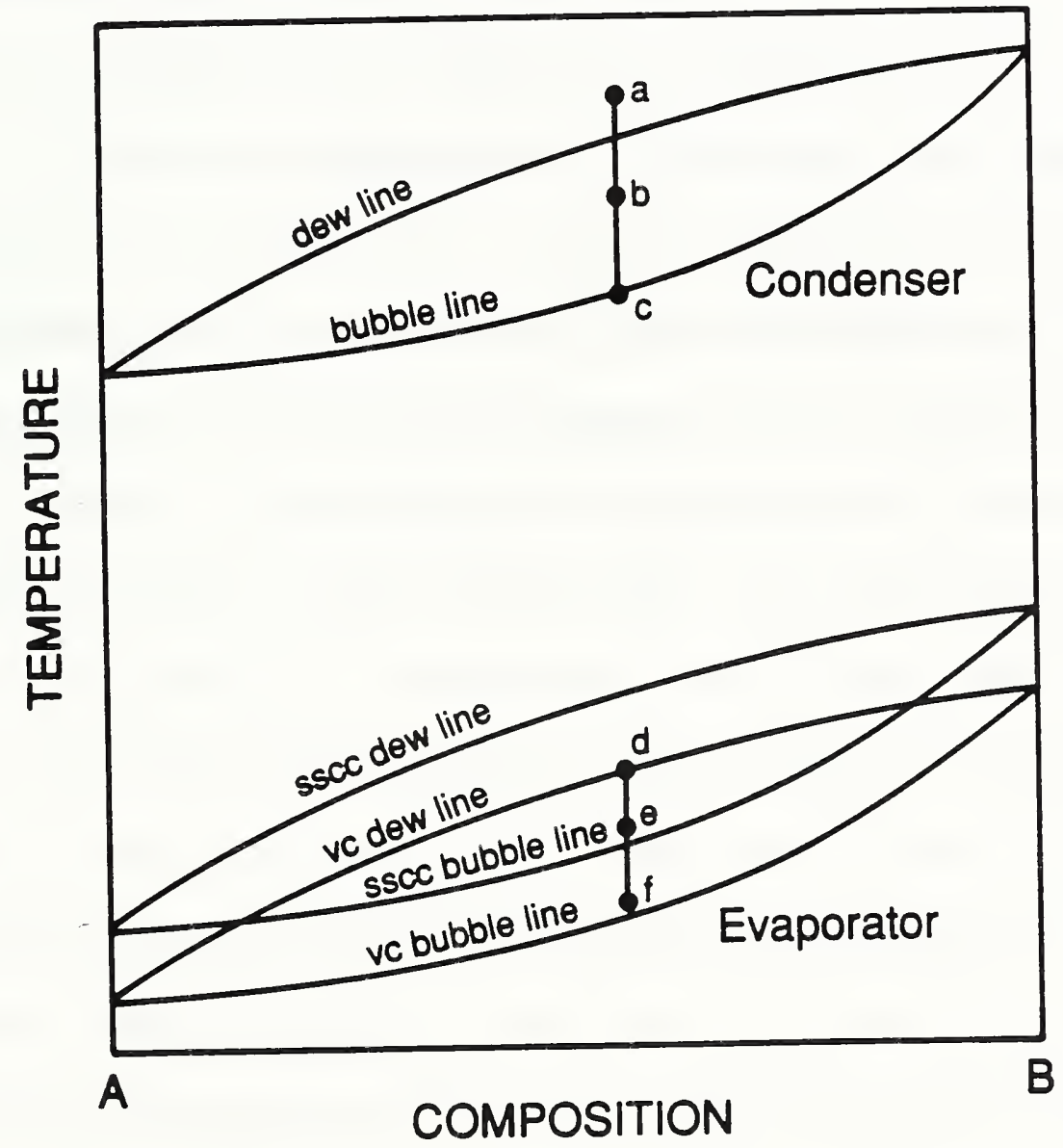

Figure 8: Temperature vs. composition diagram comparison of single solution circuit and vapor compression cycles. 
A detailed description of the apparatus and its instrumentation is given in [3]. The system works as a water-to-water heat pump. The evaporator, including its water loop, is surrounded by a calorimeter box. The primary measure of capacity is the sum of the electrical heat within the calorimeter box (pumps and resistance heaters) and the heat gain through the calorimeter wall. Condenser heat is rejected to the environment through a heat exchanger to the building brine loop. The system employs a positive displacement compressor designed for refrigerant R22, driven by a variable speed motor through a shaft dynamometer. The compressor is cooled by its suction vapor. All tests described in this report were performed using the evaporator configuration of the breadboard heat pump with the highest overall heat transfer coefficient (described as configuration 4 in [3]).

The breadboard heat pump used for a previous study [3] at NIST was modified to the single solution circuit cycle by installing a liquid pump connecting the evaporator with the condenser. Figure 9 shows in detail the solution circuit portion of the cycle. The pump is fed by liquid refrigerant from an accumulator at the outlet of the evaporator. A sight glass was installed at the pump inlet to observe the liquid stream into the pump. The liquid line coming from the condenser and the pump line exchange heat in a compact heat exchanger. A differential pressure gauge is attached in the pump line to determine the pressure loss in this heat exchanger. There are thermocouples at the inlet and outlet of the pump, the inlet and outlet and in the middle of the compact heat exchanger and before the inlet to the condenser. 


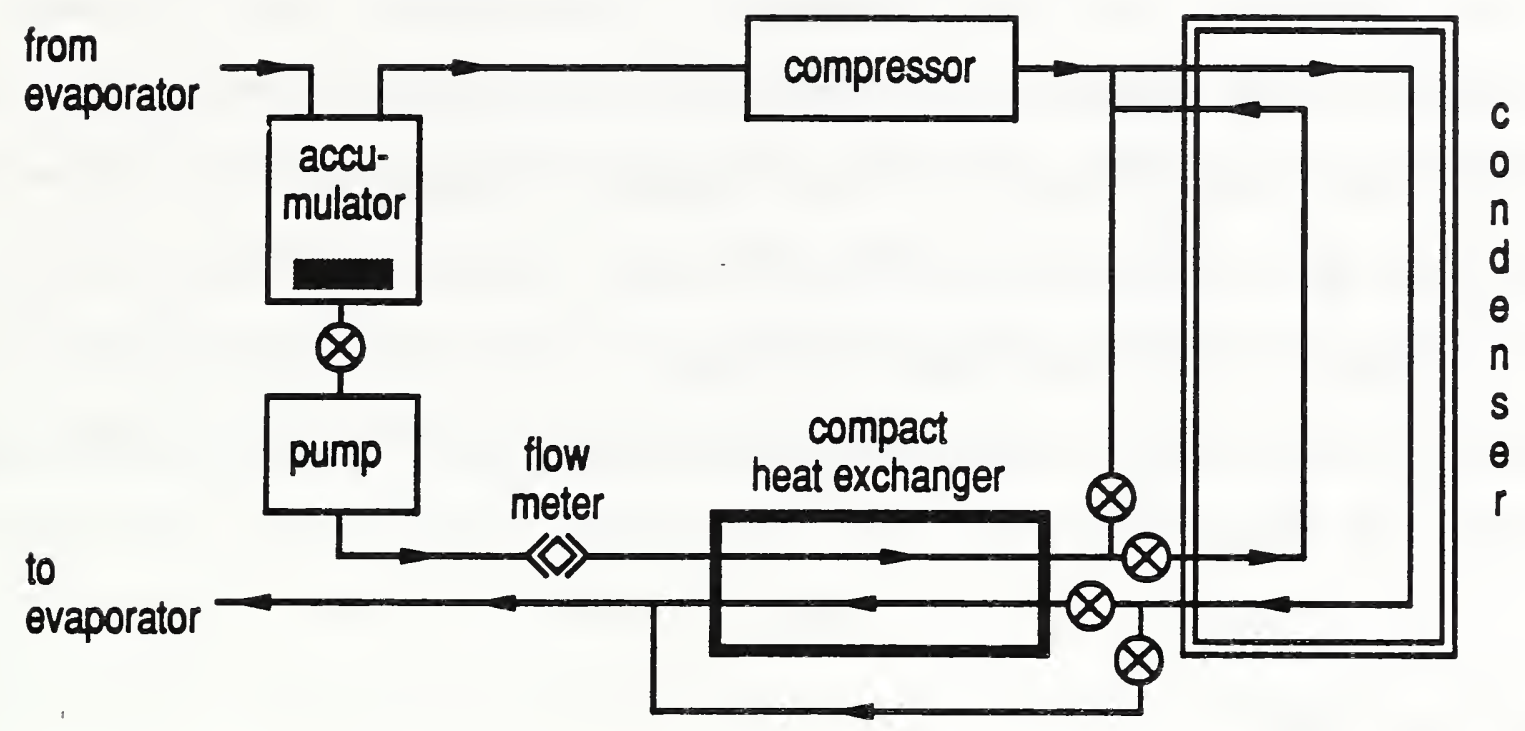

Figure 9: Schematic detail drawing of the as-installed single solution circuit cycle.

Since the liquid in the accumulator is at saturation it was necessary to raise the height of the accumulator to create sufficient static head pressure (approximately five feet) to overcome pressure drop in the connecting piping so as to prevent cavitation at the pump inlet. The pump discharge line is equipped with a sight glass, a flow meter, and a check valve to prevent gas from flowing back through the pump line when the pump is not being used. In addition, the pump line has check valves in the pump body and manual valves to shut off the line. The pump is a reciprocating, dual plunger, positive displacement diaphragm pump using oil to impart energy from the plungers to two flexible, balanced diaphragms which in turn create pumping action. The diaphragms are driven by a worm gear to eccentric to plunger to oil to diaphragm drive. 
It is also possible to run the refrigerant in the pump line first through a third passage of the condenser coil and then to the inlet of the condenser. A more detailed description of the third passage is given in [3]. This configuration was not used for these test runs. In the liquid line it is possible to bypass the compact heat exchanger. This was always done when the system was run in the vapor compression cycle mode. A sketch of the new pump line is given in Figure 9.

\section{Test Procedure}

The nonazeotropic refrigerant mixture R22/R11 was chosen for these tests. Tests were conducted at 5300, 9000, and $16500 \mathrm{Btu} / \mathrm{hr}$ evaporator capacity. All mixture tests with less than 30 of of R22 in the mixture were done at $9000 \mathrm{Btu} / \mathrm{hr}$ capacity since, for a higher capacity, the speed of the compressor and the system pressure drops would have been excessive. For these same reasons, pure R11 was rested at the still lower capacity of $5300 \mathrm{Btu} / \mathrm{hr}$. Otherwise, the constant heat flux comparability criterion as recommended in [9] was followed (i.e., constant heat flux per unit area of the evaporator).

The water temperatures for the heat sink and the heat source were kept constant for all tests. The water temperatures were $82^{\circ} \mathrm{F}\left(\approx 28^{\circ} \mathrm{C}\right)$ and $117^{\circ} \mathrm{F}$ $\left(\approx 47^{\circ} \mathrm{C}\right)$ entering and leaving the condenser, respectively, and $80^{\circ} \mathrm{F}\left(\approx 27^{\circ} \mathrm{C}\right)$ and $55^{\circ} \mathrm{F}\left(\approx 13^{\circ} \mathrm{C}\right)$ entering and leaving the evaporator, respectively. For constant capacity and a given temperature glide in the heat exchanger, the mass flow rate in the water loops is, consequently, also fixed. The compressor speed had to be adjusted for each test to meet the required constant capacity criterion as the mixture composition was changed. 
The test series were started with pure R11. The overall composition in the system was changed by adding pure R22. The first tests after each change of the total composition were in the vapor compression mode. This cycle gives the highest temperature glide for the refrigerant through the evaporator. The temperature glide, when greater than the water glide, was then decreased by employing the solution circuit pump. The expansion device was opened to allow a higher flow rate (needed because of the higher solution pump speed) but to still maintain subcooling after the condenser. Subcooling was checked by the disappearance of bubbles in the sight glass after the condenser. The temperature glide in the evaporator was decreased in small intervals from test to test by increasing the pump speed to find the point of maximum COP. Also, the compressor speed had to be adjusted for each test as a result of the changing capacity resulting from changes in glide matching as a result of variation in solution pump speed.

Tests were run with the system charged throughout the whole composition range from pure R11 to pure R22. The sampling procedure for determining mixture composition (by gas chromatography) for the vapor compression cycle is described in reference [3]. For the single solution circuit cycle additional liquid samples were taken before the expansion device and in the pump line after the solution pump. Special sample bottles had to be designed and built for this purpose. These bottles consist of two cylinders, a very small one to take the liquid sample and a large one to evaporate the liquid by expanding pressure into superheated vapor. These cylinders are connected by valves. At least two samples were taken at each line to 
validate the result of the gas chromatograph. It was very important to remove all refrigerant from the sample bottle lines before connecting them to the gas chromatograph since refrigerant $\mathrm{R} 11$ tended to remain in these lines. To obtain accurate measurements it was also necessary to clean these bottles frequently. Oil was brought into the bottles by the liquid refrigerant. Since R11 is more soluble in oil than R2?, this would have affected the analyses resulting in erroneously high $R 11$ values had the bottles not been regularly cleaned of oil.

\section{Error Analysis}

An error analysis has been conducted for the equation used to compute the efficiency of the system. The efficiency is given by

$$
\begin{aligned}
& \operatorname{COP}=\frac{\text { Capacity of Evaporator }}{\text { Work }} \\
& =\frac{q_{e 1 e c}+q_{p u m p, e v a}+q_{\text {w11,eva }}}{W_{\text {compr }}+W_{p u m p, s}}
\end{aligned}
$$

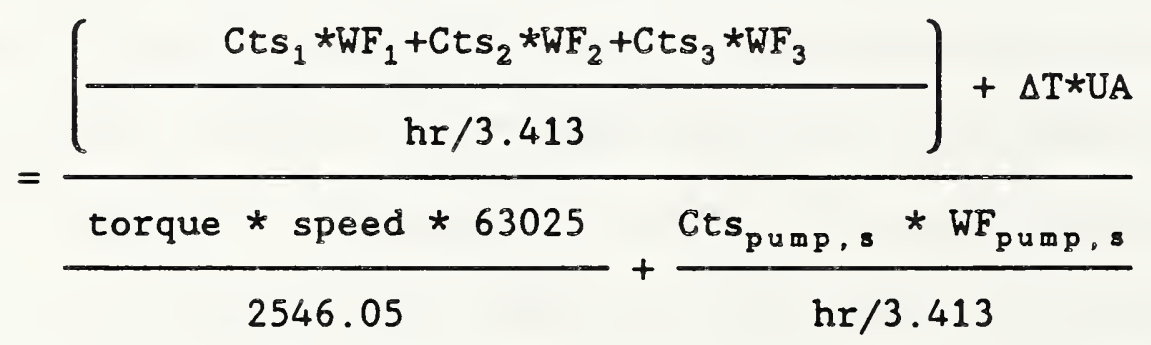

$$
\begin{aligned}
& \text { where: } q_{\text {elec }} \text { = Resistance heat inside evaporator calorimeter, } W \\
& \mathrm{q}_{\mathrm{pump}, \mathrm{eva}}=\text { Evaporator water loop pump power, } W \\
& \mathrm{q}_{\mathrm{wall}, \mathrm{va}}=\text { Heat gain through evaporator calorimeter wall, } \mathrm{W} \\
& \mathrm{W}_{\text {compr }}=\text { Compressor dynamometer power, } W \\
& \mathrm{~W}_{\mathrm{pump}, \mathrm{s}} \quad \text { Solution pump power, } \mathrm{W} \\
& \text { Cts }=\text { Watthour meter counts during test period }
\end{aligned}
$$


WF $\quad$ Function for converting watthour meter counts to watts

hr $\quad=$ Length of test, $h$

$\Delta \mathrm{T} \quad=$ Calorimeter internal-external temperature difference, ${ }^{\circ} \mathrm{F}$

TIA = Calorimeter overall thermal conductivity, $W /{ }^{\circ} \mathrm{F}$

torque = Dynameter torque, inch-pounds

speed = Dynameter speed, revolutions per minute

The absolute error of the quantity $N=f\left(u_{1}, u_{2}, u_{3}, \ldots . u_{n}\right)$ is given by

$$
\Delta N=\left|\Delta u_{1} \frac{\partial f}{\partial u_{1}}\right|+\left|\Delta u_{2} \frac{\partial f}{\partial u_{2}}\right|+\ldots .+\left|\Delta u_{n} \frac{\partial f}{\partial u_{b}}\right|
$$

This form of the error equation gives the largest error that is possible and shows which variables exert the strongest influence on the accuracy of the overall result. The relative error is

given by

$$
N_{s}=\frac{\Delta N}{N} * 100
$$

The highest calculated relative error in COP that occurred was $8 \%$. The relative errors at the three test capacities, $5300 \mathrm{Btu} / \mathrm{hr}, 9000 \mathrm{Btu} / \mathrm{hr}$ and 16500 $\mathrm{Btu} / \mathrm{h}$ are approximately $8.08,5.28$ and 2.98 , respectively. Calculation details for Figure 10 are given in the Appendix.

The relative error is insensitive to changes in speed but strongly affected by evaporator capacity. This is because accuracy of measuring the capacity of the evaporator is worse than the accuracy of measuring the speed. 


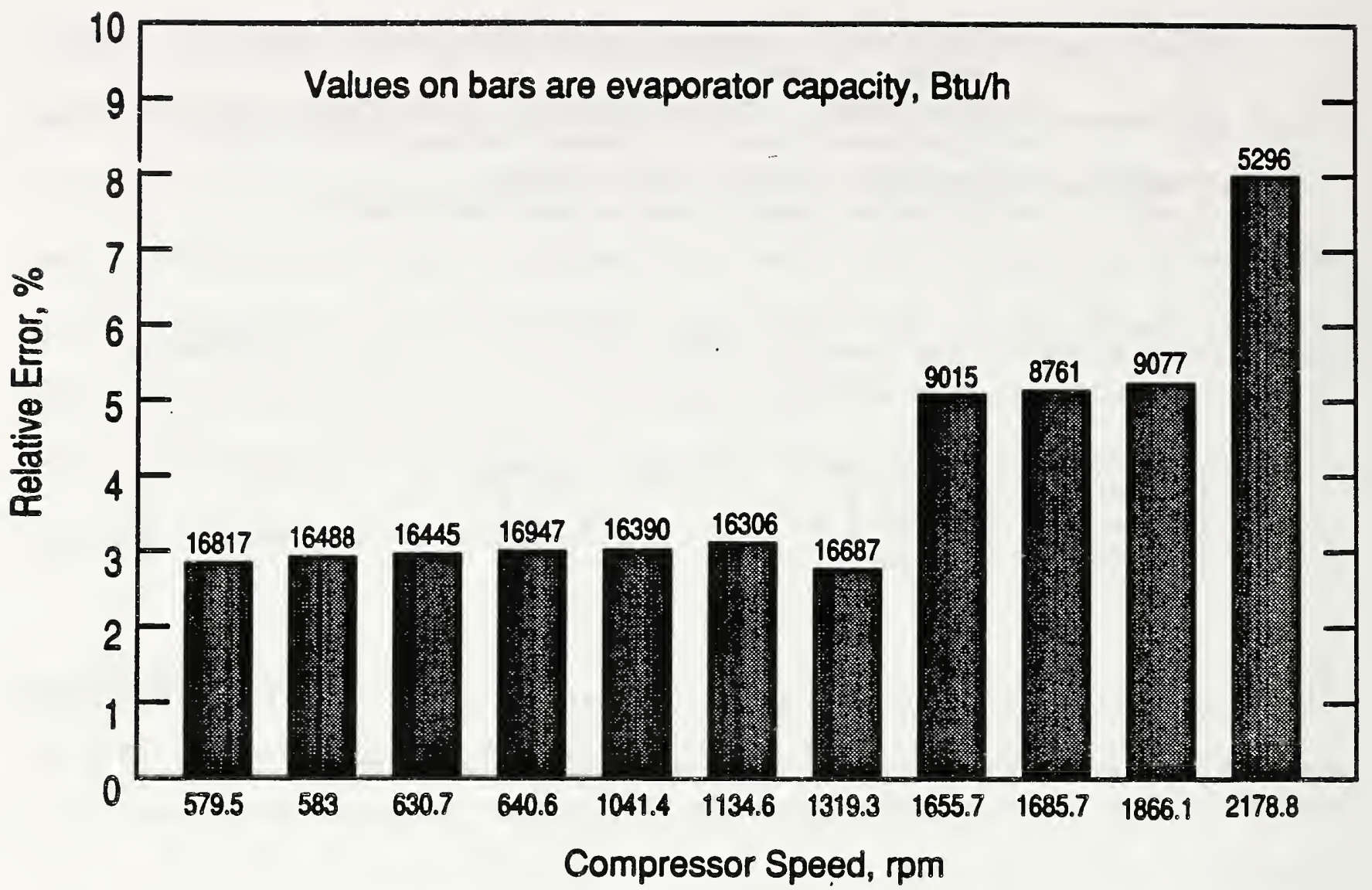

Figure 10: Relative errors in COP measurement.

\section{Test Results}

\subsection{Compressor Mechanical Losses}

These compressor loss tests were run after the cycle evaluation tests described later in this report when it was observed that compressor efficiency was greatly reduced at high concentrations of R11. However, understanding of the cycle evaluation tests is easier if this topic is covered first.

To evaluate the compressor mechanical losses (friction losses) the compressor power was measured while operating in vacuum for a short time for increasing and decreasing speeds. The result is shown in Figure 11. The graph shows an approximately linear function (regression yields an exponent of 1.3) between speed and mechanical losses. 


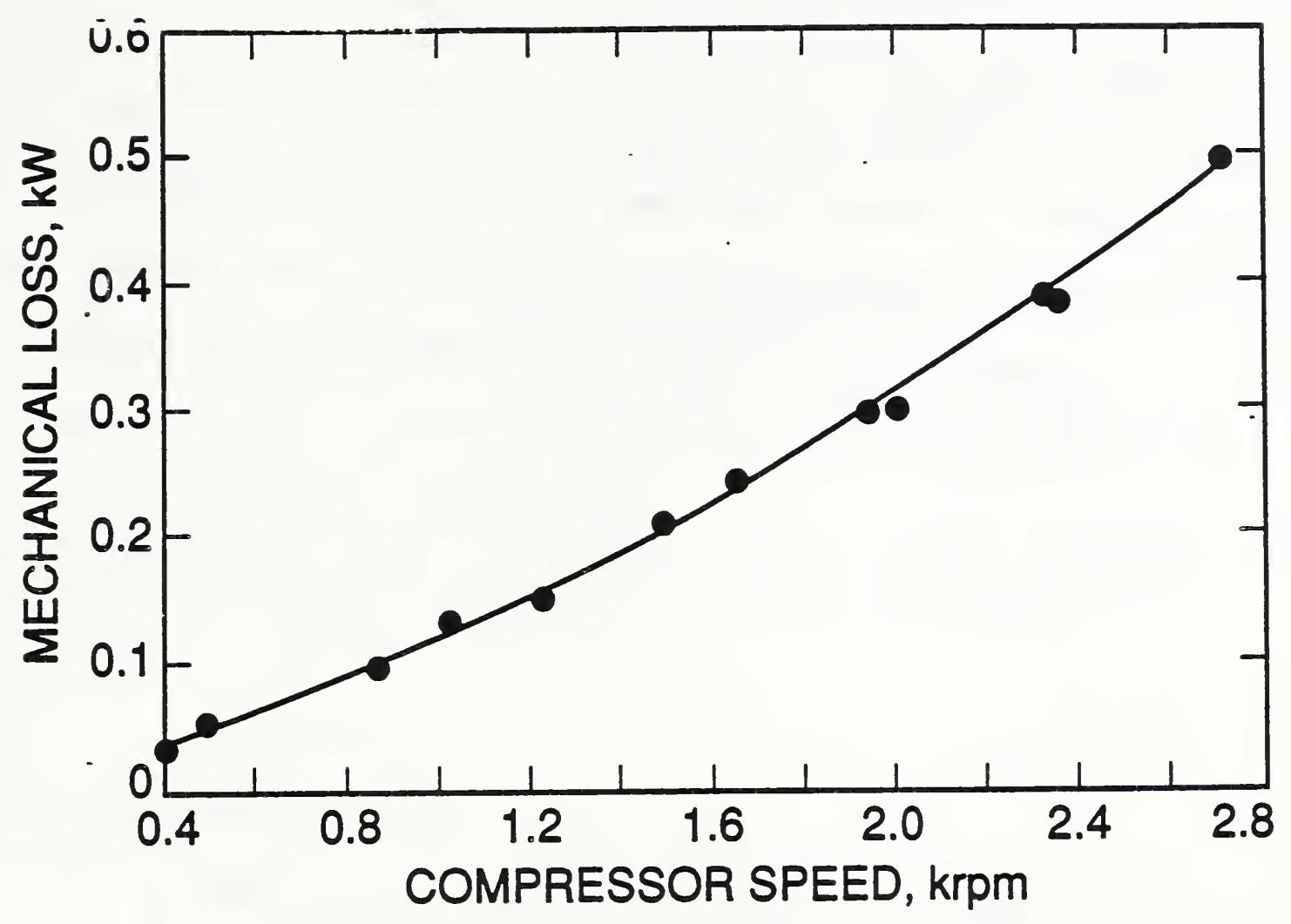

Figure 11: Compressor friction loss.

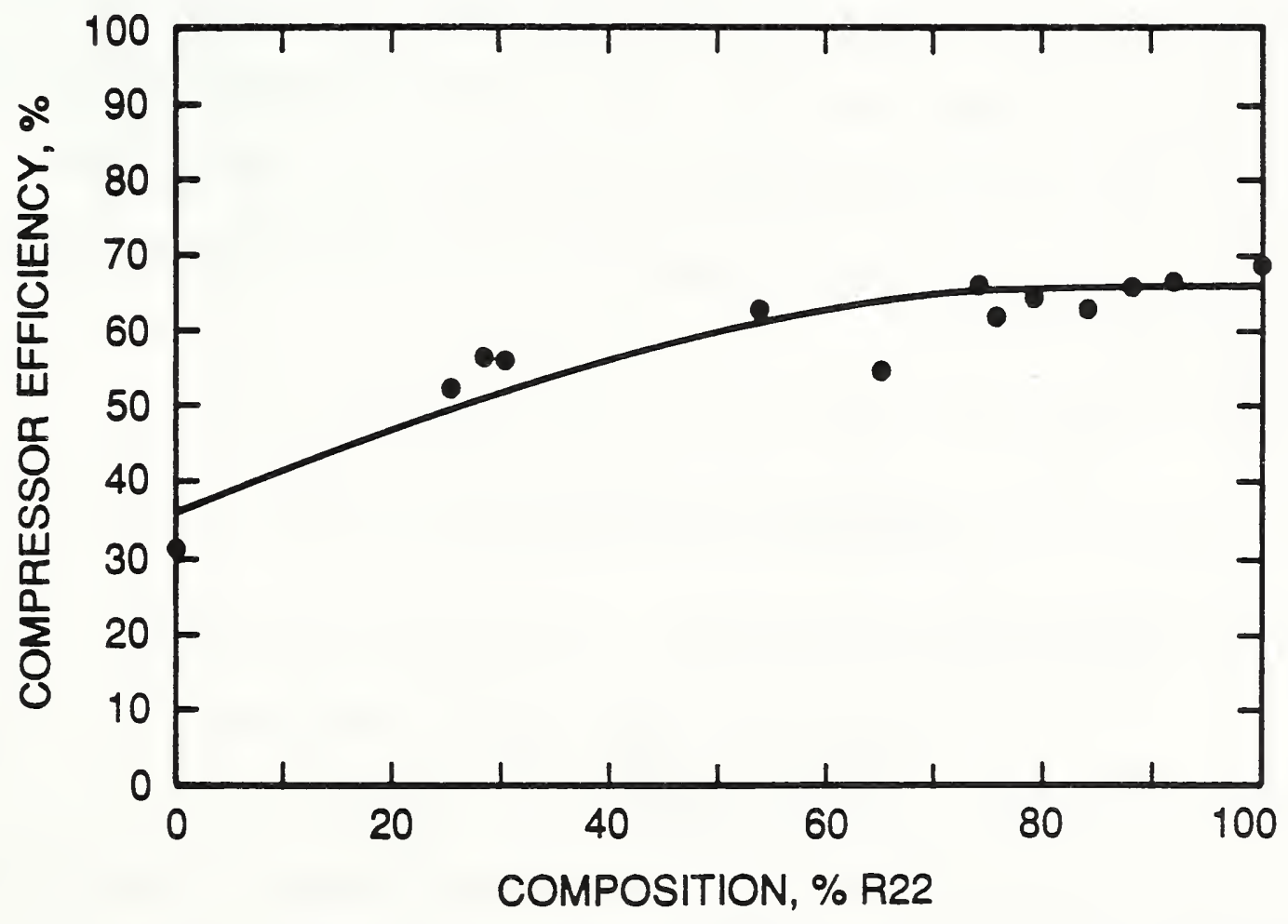

Figure 12: Compressor efficiency vs. composition (experimental data). 
The inadequacies of measuring compressor mechanical losses by measuring power input when operating in a vacuum should be noted. The bearing loads would be expected to increase with pressure ratio and be at a minimum under this no-load condition. On the other hand, cylinder wall friction would be expected to increase at this no-refrigerant-flow test condition since there would be no oil mist carry over in circulating refrigerant. In summation, there are shortcomings in this test procedure; however, it is all that can be done to measure mechanical losses without severely modifying the compressor. The fairly constant resulting corrected efficiency (Figure 13) suggests it is a useful approach.

Compressor tests do not show great variation in mechanical efficiency as a fraction of total capacity when they are run with a pure component at different speeds and the corresponding capacities. In such a case, capacity and mechanical losses increase in nearly the same ratio, and therefore, there is little effect on their ratio [3]. When running mixture tests at constant capacity the speed of the compressor is different for each mixture. Therefore, the mechanical losses change with speed while the capacity remains the same.

The efficiency of the compressor has been calculated for several tests. The compressor efficiency is defined as:

$$
\text { compressor efficiency }=\frac{\text { isentropic work }}{\text { shaft power }}
$$

The results are shown in Figure 12 . 
The compressor efficiency can be seen to change from approximately 35 for pure R11 to 70 for pure R22. To evaluate the influence of compressor mechanical loss, the compressor efficiency was redefined as:

cor. compressor efficiency $=\frac{\text { isentropic work }}{\text { shaft power - mechanical loss }}$

Figure 13 shows the graph of mechanical loss corrected compressor efficiency as a function of mixture composition.

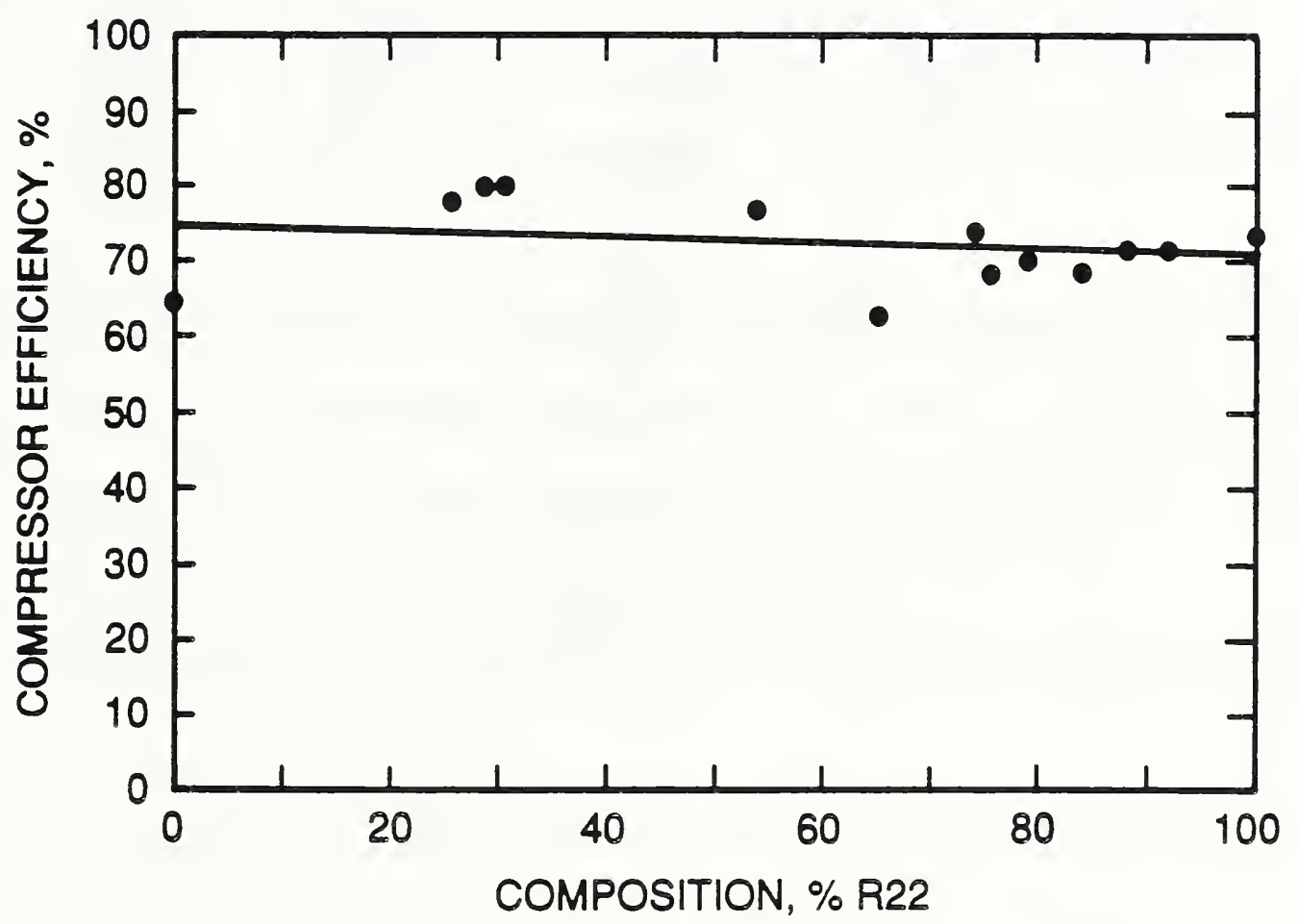

Figure 13: Compressor efficiency vs. composition (experimental data corrected for mechanical losses).

The graph shows a comparatively constant corrected compressor efficiency band ranging from $65 \%$ to $80 \%$. Similar results are shown in Table I in which data for the pure refrigerants R12 and R114 taken from [3] are compared to 
the pure R22 and R11 data of this report. This indicates the strong influence of mechanical loss effects on system efficiency for changing mixture compositions.

Table I: Compressor Efficiency for pure R22, R12, R114, and R11.

Refrigerant

System Capacity, Btu/h

Dynamometer Power, $W_{D}, B t u / h$

System COP

Comp. Suction Pressure, psia

Comp. Suction Temperature, ${ }^{\circ} \mathrm{F}$

Comp. Discharge Pressure, psia

Isentropic Work on Refrigerant, $\mathrm{W}_{\mathrm{s}}, \mathrm{Btu} / \mathrm{h}$

Comp. Speed, rpm

Volumetric Capacity, Btu/revolution

Mechanical Loss, $W_{\mathrm{L}}, \mathrm{Btu} / \mathrm{h}$, Figure 11

Efficiency, $W_{S} / W_{D}$, equation 4

Corrected Efficiency, $W_{S} /\left(W_{D}-W_{L}\right)$, equation 5

\begin{tabular}{c|c|c|c|}
22 & 12 & 114 & 11 \\
14,170 & 18,400 & 7030 & 5300 \\
2740 & 4200 & 2020 & 2360 \\
5.17 & 4.38 & 3.48 & 2.25 \\
104.5 & 59.5 & 17.1 & 8.2 \\
60.3 & 55.7 & 65.1 & 77.0 \\
146.9 & 164.2 & 63.4 & 30.0 \\
1945 & 2730 & 1050 & 755 \\
504 & 1130 & 1200 & 2180 \\
28.1 & 16.3 & 5.9 & 2.4 \\
155 & 530 & 570 & 1165 \\
.71 & .65 & .52 & .32 \\
.75 & .74 & .72 & .63
\end{tabular}

This approach to handling compressor efficiency (equation 5) was previously presented in [10] as a means for correcting experimental data for purposes of comparison. The logic behind this approach depends on three basic assumptions. First, constant isentropic efficiency in the compression process. Second, that the isentropes are parallel/on the $\mathrm{p}$-h diagram. Third, that the shaft work into the cycle can be represented as heating the refrigerant before compression with the heat equivalent of the compressor mechanical losses followed by the work of compression.

These assumptions are illustrated in Figure 14. An ideal vapor compression cycle with isentropic compression is represented as afgb. A nonisentropic compression process is represented by replacing gb with gc. Mechanical losses are represented by gh. Compression after addition of the heat of mechanical 
losses is represented isentropically as hd and nonisentropically as he.

Constant isentropic efficiency implies that the isentropic and nonisentropic compression curves diverge at the same fixed rate for both bcg and deh. If this is the case, bc will equal de. The shaft work into the cycle is ge. If the isentropes are parallel and bc equals de (as was above presumed), then gc will equal ge minus gh. Thus, equation 5 is a good approximation of the isentropic efficiency, $\mathrm{gb} / \mathrm{gc}$.

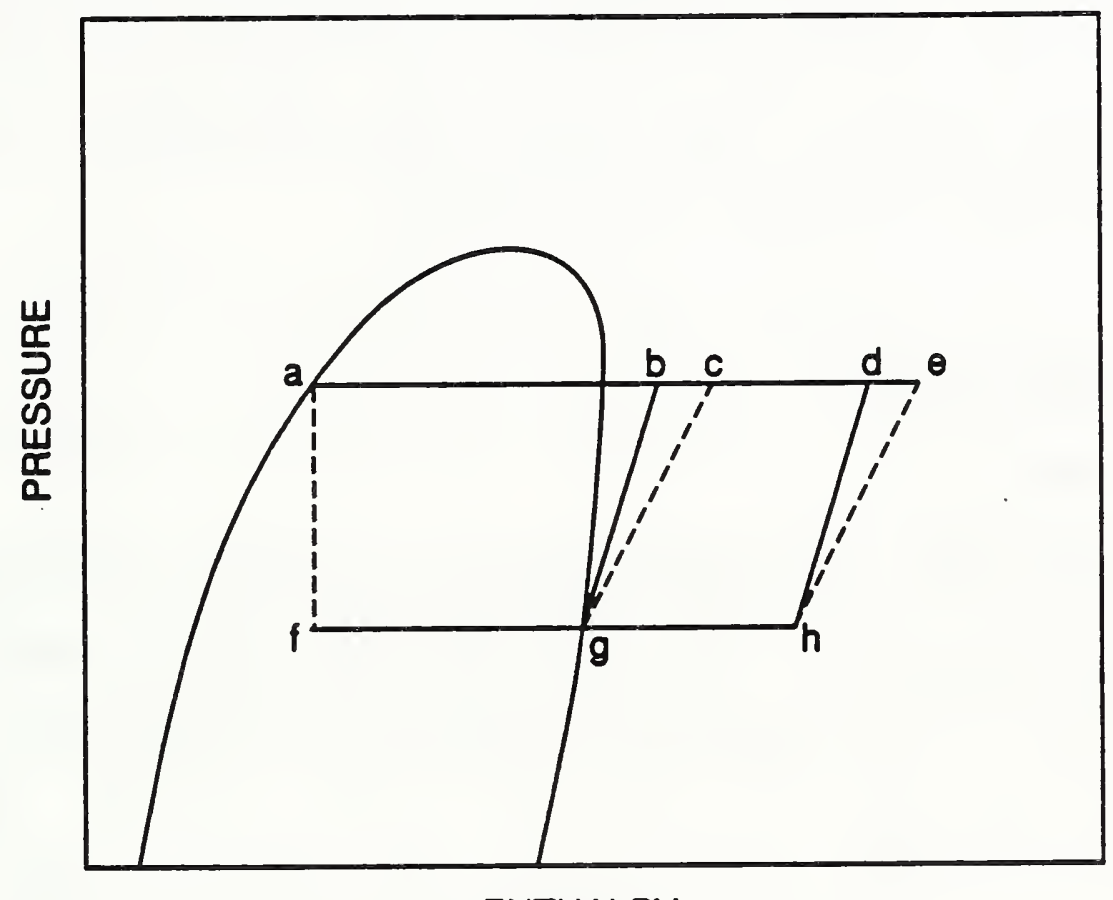

ENTHALPY

Figure 14: Pressure-enthalpy representation of compressor mechanical losses.

In summary, the argument is being presented in this section that piston compressor efficiency is better modeled by equation 5 in conjunction with Figure 11 than it would be modeled by the traditional approach of a constant ratio of isentropic work to the actual work on the refrigerant multiplied by a constant mechanical efficiency. The experimental validation of this argument, i.e., an approximately constant equation 5 efficiency, while it employed a wide range of refrigerants, is limited to one compressor. Other compressor 
designs with higher jacket loss or of different design (rotary, scroll, screw, and especially centrifugal) would be expected to perform differently.

The result of the discussed compressor mechanical losses is inherently low system efficiency when operating with a low capacity refrigerant (in this case mixtures rich in R11). It does not matter whether constant speed or variable speed operation is employed. In the former case the mechanical loss stays constant and the capacity is reduced. In the latter case, the capacity would stay the same but the mechanical loss would be increased.

\subsection{Vapor Compression Cycle}

1. COP versus Composition

The results for the vapor compression cycle run under the conditions as described in chapters 3 and 4 ("Test Apparatus" and "Test Procedure") are shown in Figure 15.

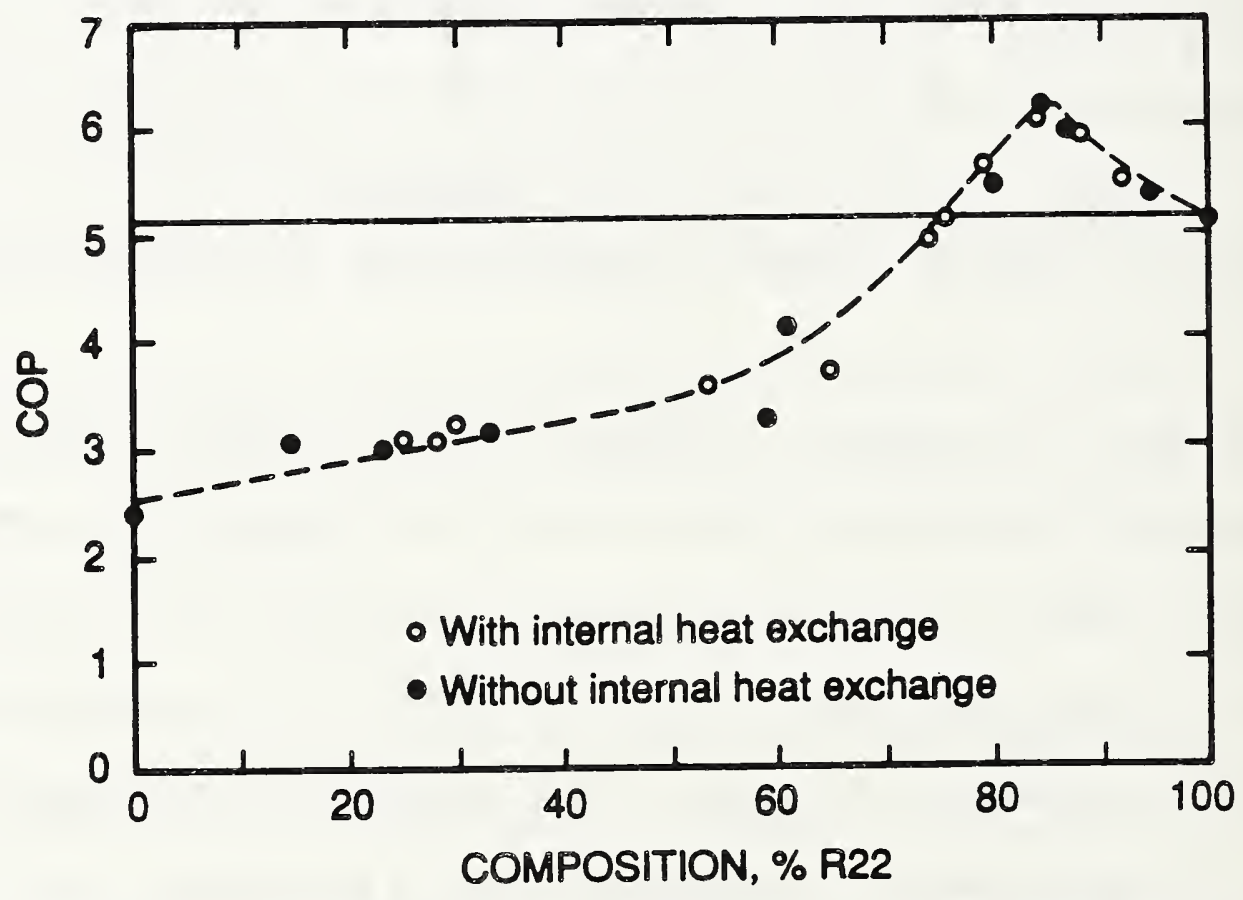

Figure 15: COP vs. composition for the vapor compression cycle (experimental data). 
Figure 15 shows no difference in performance for the cycle working with or without internal heat exchange. This is consistent with the nonlinear temperature versus enthalpy relationship in the two-phase region of this refrigerant mixture. At high concentrations of R22, the temperature enthalpy curve was essentially flat at low qualities resulting in little temperature change with increased subcooling. At low concentrations of R22, there was a high but nonlinear temperature gradient at low qualities resulting in a lower temperature but increased irreversibilities with increased subcooling. At intermediate concentrations of R22, glide matching was so poor as to obviate any effect from this cycle modification. Thus, only one line is drawn into this graph regardless of internal heat exchange.

The COP improved by 198 at a composition of approximately $848 \mathrm{R} 22 / 168 \mathrm{R} 11$ in comparison to the pure refrigerant $\mathrm{R} 22$ which is represented in the graph by $a$ horizontal line. For this highest efficiency composition the temperature glide of the evaporator water loop and the refrigerant mixture nearly matched. With an increasing amount of R11 the efficiency decreases to a value substantially under the horizontal line of the pure R22 COP due to mismatch of the temperature profiles. The second maximum, as predicted in Figure 5, is not discernible. The cycle employing pure R11 has the lowest efficiency of the whole composition range.

In the ideal cycle the temperature glides of the refrigerant mixture in evaporator and condenser perfectly match the temperature glides of the heat source and heat sink. Under the given conditions for all tests with the mixture R22/R11 it was not possible to match the temperature glide in evaporator 
and conoenser at lite saine time. The evaporator conditions were carefully monitored. At matching temperature glides between the working fluid and the heat source the temperature profiles in the condenser mismatch. This mismatch results in a lower efficiency and causes a small shift of the highest COP toward a different composition since the optimum composition is the one which minimizes the irreversibilities in both evaporator and condenser.

There are three primary reasons for the poor performance of the vapor compression cycle using a mixture high in R11. Their effects are shown separately and cumulatively by computer simulation in Figure 16. First, is pressure drop. The constant heat flux test criteria [9] was met by increasing compressor speed but the resulting pressure drops in the refrigerant piping were not compensated for by size increases. Second, is nonlinearity of enthalpy and entropy as a function of temperature in the two-phase region as exemplified in Figures $3 b$ and $3 c$. This prevents full advantage being taken of glide matching. Third, is compressor efficiency changes which were felt to be caused by changing mechanical efficiency as discussed in Section 6.1 which greatly lowers the R11 end of the efficiency curve.

The close agreement between the computer simulation with these corrections and the experimental data indicates that these are the primary non-idealities which are present and which must be added to a simple computer model for prediction of mixture performance. The model used to generate Figure 16 was 


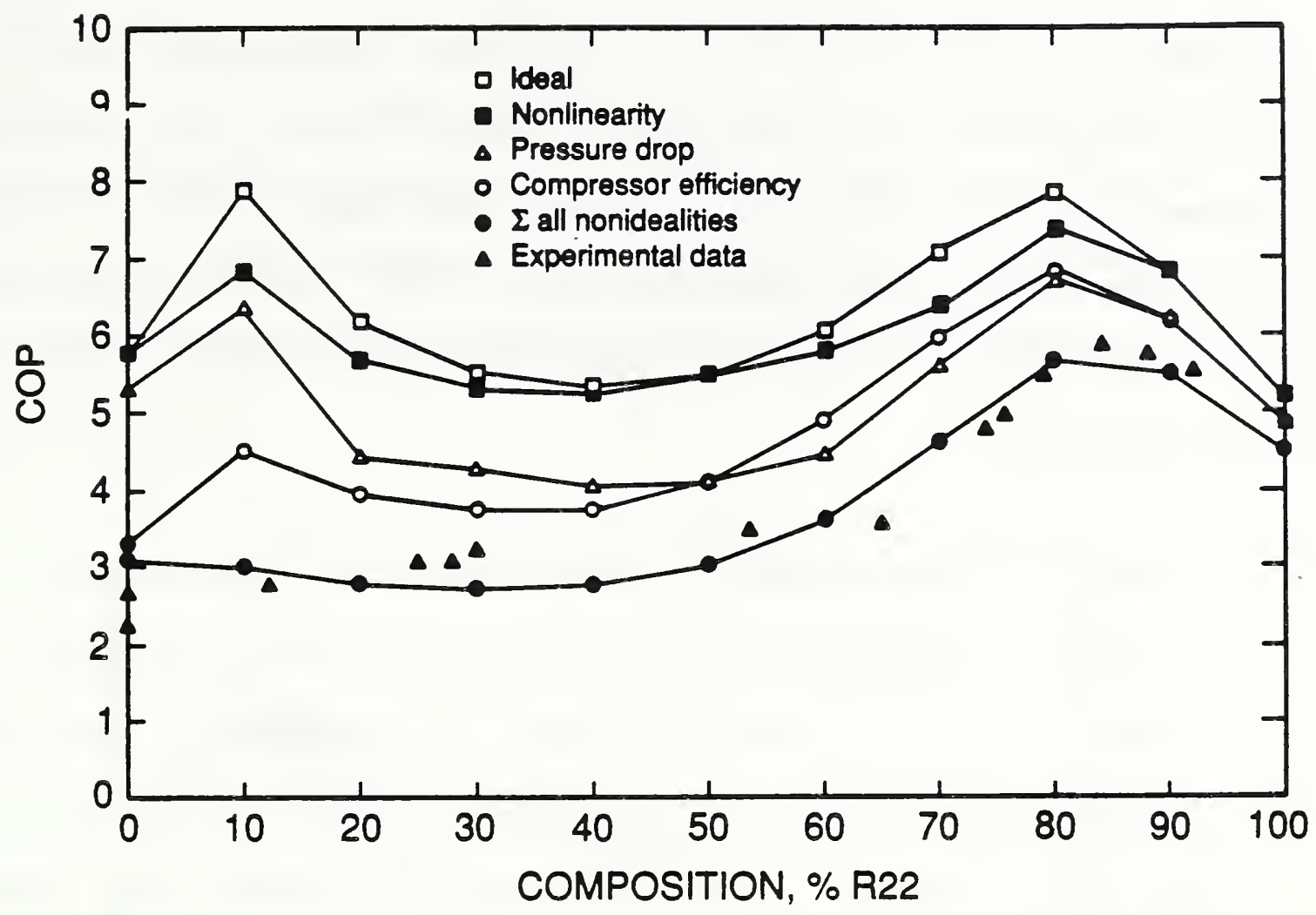

Figure 16: Comparison of computer simulation to experimental vapor compression cycle data.

not predictive for this project since the experimental compressor mechanical losses and measured test pressure drops were used as inputs. It is, however, hoped that it can be so used in the future.

\subsection{Single Solution Circuit Cycle}

Figure 17 shows efficiency versus composition for the single solution circuit cycle in comparison to the normal vapor compression cycle. Each single solution circuit cycle data point in Figure 17 represents the highest efficiency test of a series of three to five tests at different solution pump speeds for each nominal concentration. For the single solution circuit cycle different mixture compositions occur in the heat exchanger and condenser liquid line, 
test of a series of three to five tests at different solution pump speeds for each nominal concentration. For the single solution circuit cycle different mixture compositions occur in the heat exchanger and condenser liquid line, the solution pump line and the compressor suction line. For all graphs the composition occurring in the heat exchangers and condenser liquid line was chosen as the abscissa.

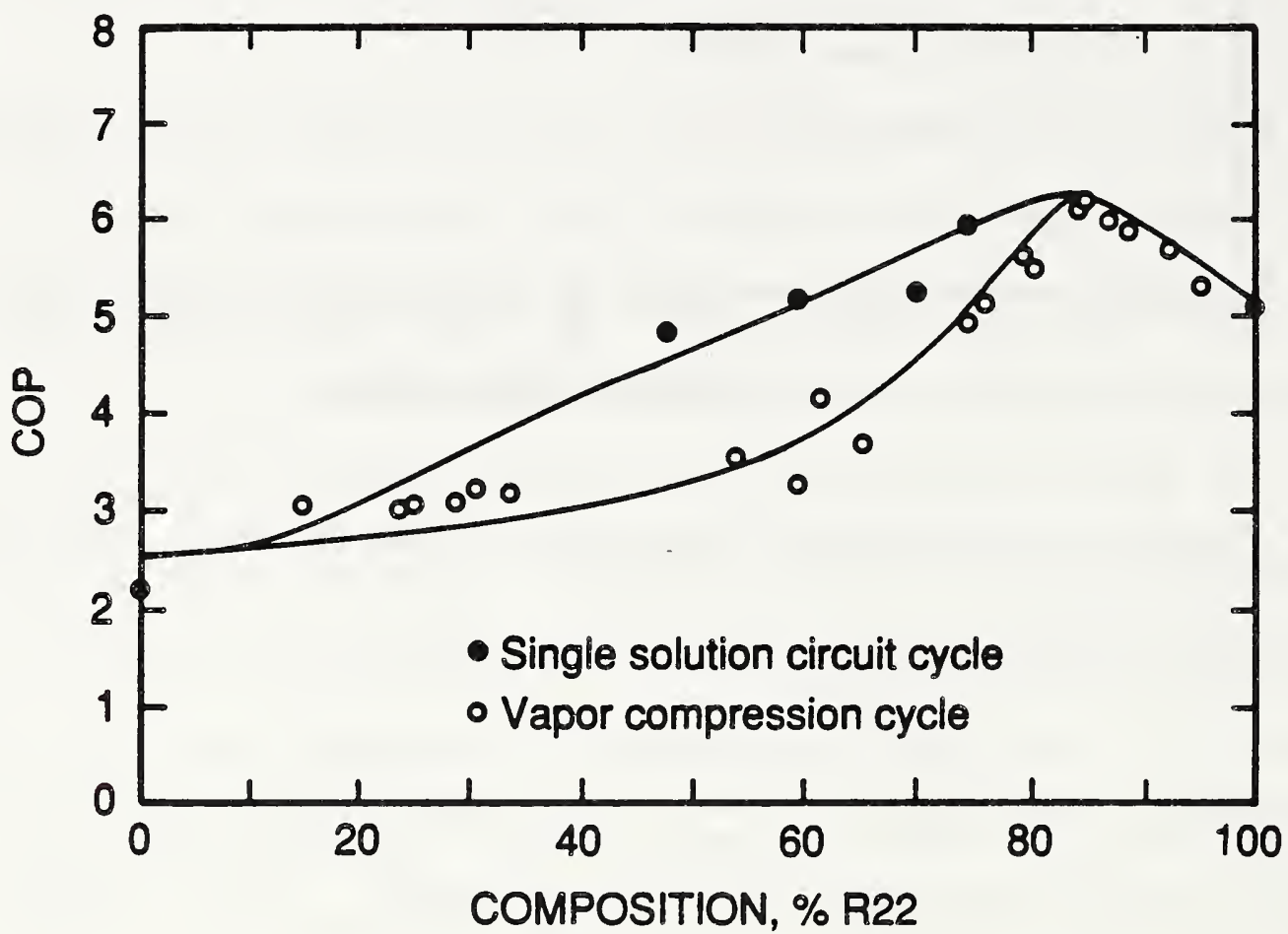

Figure 17: Comparison of COP vs. composition for the single solution circuit cycle to that of the conventional vapor compression cycle.

In the middle range of composition the efficiency is substantially improved. The highest COP is obtained by a mixture high in R22 for the conventional vapor compression cycle not using the solution pump. This corresponds to the right hand peak and divergence point between the two cycles of Figure 5 . The improved efficiency in the middle range is due to better matching of the 
temperature glide in the heat sink and heat source as well as to a lower comnressor sneed. By matching the temperature glide the irreversibilities Figure 18 are reduced, and suction pressure and, hence, capacity are increased (see Figure 3). The compressor speed is reduced to compensate for this inherently higher capacity resulting in reduced pressure drop and compressor frictional losses.

Figure 18 shows three different temperature profiles of the evaporator while changing the pump speed for a constant initial refrigerant charge. First, at low pump speed the temperature glide is too large causing unnecessary losses due to irreversibilities. Decreasing the temperature glide increases the efficiency. The maximum COP is obtained for a temperature glide similar to the evaporator temperature glide. A further glide decrease results in again smaller efficiency values. The best efficiency value is plotted into the graph of efficiency versus composition, Figure 17.

The solution pump can only improve glide matching by decreasing (not increasing) the refrigerant temperature glide. For a composition high in either R11 or R22 where the temperature glide is already less than desired it would be illogical to use the solution pump. Therefore, the solution circuit cycle is presumed to run as a vapor compression cycle at these extreme concentrations in Figures 17 and 19.

As shown in Figure 19, the improvement of the efficiency by employing the solution pump is negligible for a given volumetric capacity (as opposed to a given composition as shown in Figure 17). Referring to Figures 5 and 7, the 

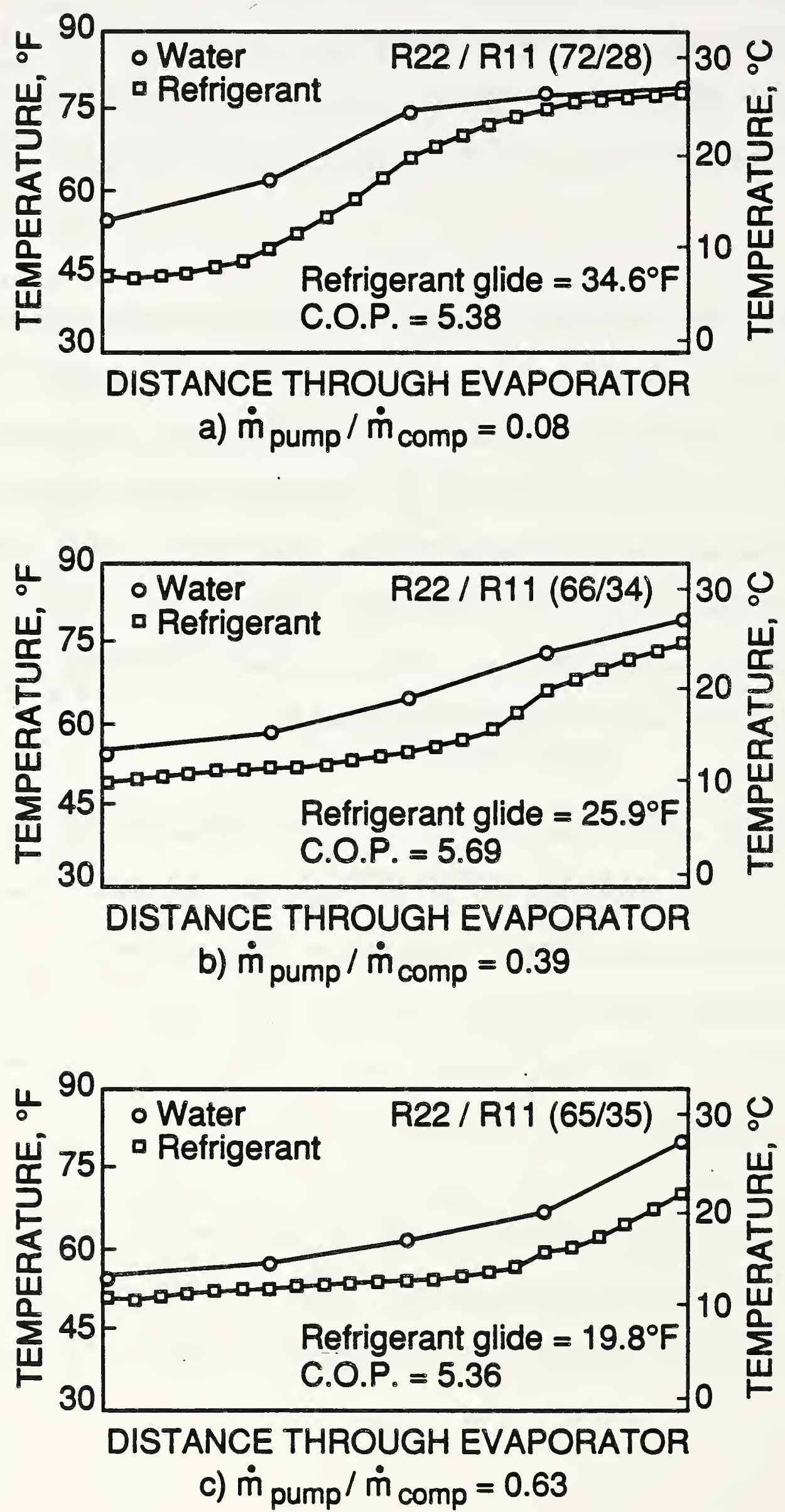

Figure 18: Evaporator temperature profiles for various solution pump speeds. 


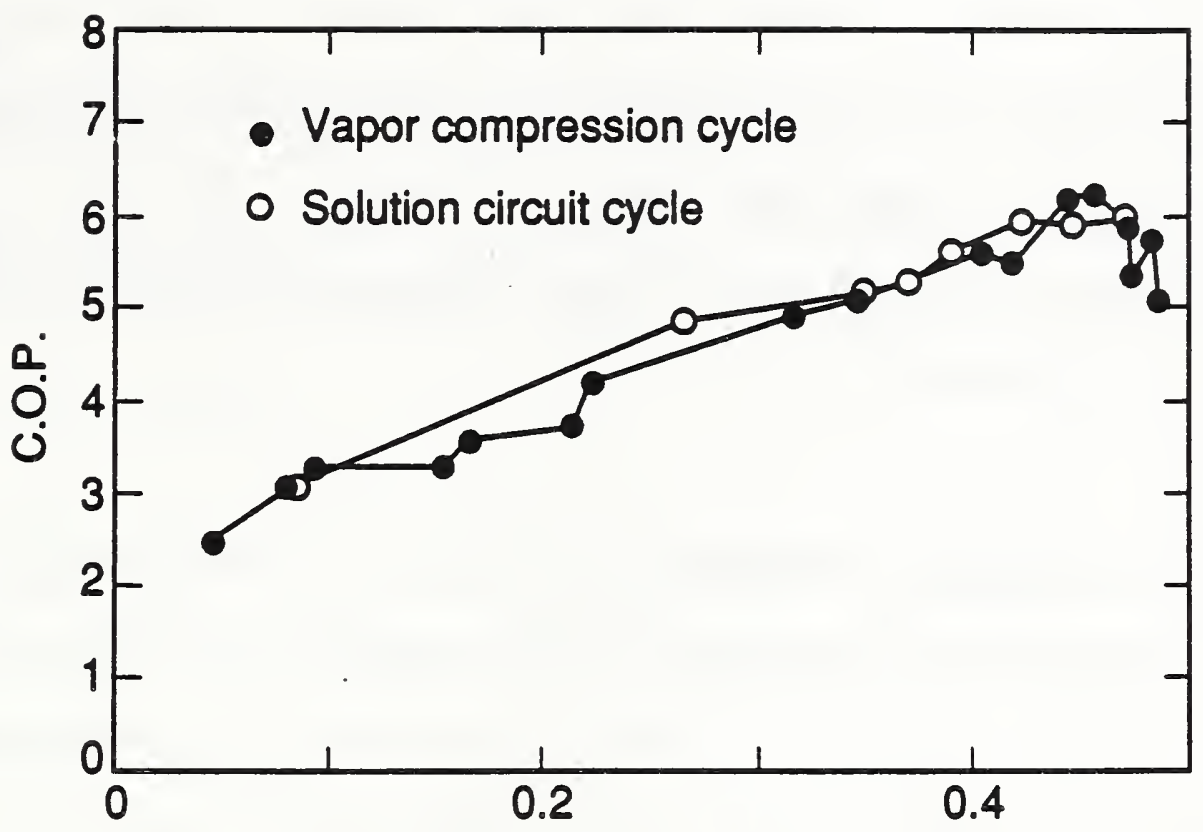

VOLUMETRIC CAPACITY, Btu per compressor revolution

Figure 19: Comparison of COP vs. capacity/revolution for the single solution circuit cycle to that of the normal vapor compression cycle.

\section{Discussion}

The application of the single solution circuit cycle that was to be demonstrated in this test series was the disassociation of glide from composition allowing simultaneous glide matching for high steady-state efficiency and composition shifting to reduce cycling losses. The cycle was demonstrated to be capable of this disassociation. However, it was demonstrated that composition shifting to significantly unload the compressor was an inefficient capacity control strategy. The use of this cycle to provide glide matching still has merit.

Inefficiency at light load (i.e. at high R11 concentrations) was caused by increased system pressure drop, nonlinearity of refrigerant enthalpy as a function of temperature in the two-phase region, and compressor frictional losses (mechanical efficiency). 
High system pressure drop at light loads was a result of the constant capacity test criteria desired as an aid to analysis. When pressure drop appeared excessive the compressor speed was, however, reduced. An actual system would be expected to operate with properly sized refrigerant lines and this problem would, hence, be eliminated.

Nonlinearity of refrigerant enthalpy as a function of temperature in the twophase region reduced gains possible by glide matching to the sensible water heat source and sink. High glide binary refrigerants are inherently nonlinear. It would appear best, when the heat source and sink are linear fluids, to use binary refrigerants only for low glide applications and to use ternary or higher order refrigerants when high glides are desired.

The final and most serious (greatest in magnitude) nonideality, compressor mechanical losses, is not so easily disposed of. It is inherent in piston compressors (as was tested). For this reason, capacity modulation by composition shifting cannot be a recommended procedure for compressor unloading where efficiency is a concern. Conversely, composition shifting to increase loading, as for low temperature heat pump operation, remains highly recommended as discussed in [5].

As stated, this cycle has demonstrated an ability to match glide and would, therefore, be of use in applications where glide changed substantially with load. In such an application the refrigerant should be selected for best glide matching and capacity control to match reduced loads should be done by conventional means (compressor cycling or speed variation). 


\section{Conclusions}

The single solution cycle demonstrated an ability to reduce refrigerant glide by solution pump speed variation as intended. This allows glide matching and system efficiency improvement without changing the composition of the circulating refrigerant by distillation.

An efficiency improvement of 198 over pure R22 was demonstrated at the chosen test conditions using the nonazeotropic refrigerant mixture $R 22 / R 11$ in the basic vapor compression cycle.

Capacity reduction for matching light loads by composition shifting was demonstrated to be an inefficient control strategy as a result of compressor friction (mechanical efficiency).

A high nonlinearity of enthalpy as a function of temperature in the twophase region was observed in the mixture tested, R22/R11. Theoretical considerations indicate that this is inherent in high glide binary refrigerant mixtures.

\section{Future Work}

The ability of the single solution circuit cycle to improve the efficiency of a system in which glide varies with load and system unloading is assumed to be provided by conventional means should be investigated using a highly linear refrigerant mixture known to have good efficiency in the compressor type used for the study. 
1. Burr, P.S., Haseldon, G.G., "A Non-isothermal Mixed Refrigerant Cycle for Air-Conditioning Duties", Proceedings of the Institute of Refrigeration, Volume 71, London, England, 1974-75.

2. Jakobs, R., Kruse, H., "The Use of Non-azeotropic Refrigexant Mixtures in Heat Pumps for Energy Saving", Proceedings of IIR Commission B2, Delft, the Netherlands, 1978 .

3. Kauffeld, M., Mulroy, W., McLinden, M., and Didion, D., "An Experimental Evaluation of Two Nonazeotropic Refrigerant Mixtures in a Water-to-Water Breadboard Heat Pump", NISTIR 90-4290, National Institute of Standards and Technology, Gaithersburg, MD.

4. Cooper, W.D., "The Use of Mixed Refrigerants in Air-to-Air Heat Pumps", ASHRAE Transactions, Volume 88, Pt. 1, American Society of Heating, Refrigerating and Air Conditioning Engineers, Inc., Atlanta, GA 1982.

5. Mulroy, W. and Didion, D., "The Performance of a Conventional Residential Sized Heat Pump Operating with a Nonazeotropic Binary Refrigerant Mixture", NBSIR 86-3422, National Bureau of Standards, Gaithersburg, MD 1986.

6. Altenkirch, E., "Vapor Compression Refrigerator with Solution-Circulation", Kaeltetechnik, February, 1950.

7. Radermacher, R., "Heat Pump Cycle with Solution Circuit and Internal Heat Exchange", Industrial Energy Conference and Exhibit, 1986.

8. Vakil, H., "Means and Method for the Recovery of Expansion Work in a Vapor Compression Cycle Device", United States Patent No. 4034099, 1981.

9. McLinden, M.O., Radermacher, R., "Methods for Comparing the Performance of Pure and Mixed Refrigerants in the Vapor Compression Cycle", International Journal of Refrigeration, Volume 10, No. 6, 1987. 
10. Stoecker, W. and McCarthy, C., "The Simulation and Performance of a System Using an R12/R114 Refrigerant Mixturen, ORNL/Sub/81-7762/3\&01, Oak Ridge National Laboratory, Oak Ridge, TN, 1981. 
The partial altferentials of equation (1) for equation (2) are:

$\frac{\partial f}{\partial h r}=\frac{k_{4} k_{2}-k_{1} k_{3}}{(h r)^{2} *\left(k_{3}+\frac{k_{4}}{h r}\right)^{2}}$

$\frac{\partial f}{\partial \text { torque }}=\frac{-\left(\frac{k_{1}}{h r}+k_{2}\right) * \frac{k_{3}}{\text { torque }}}{\left(k_{3}+\frac{k_{4}}{h r}\right)^{2}}$,

$\frac{\partial f}{\text { aspeed }}=\frac{-\left(\frac{k_{1}}{h r}+k_{2}\right) * \frac{k_{3}}{\text { speed }}}{\left(k_{3}+\frac{k_{4}}{h r}\right)^{2}}$,

$\frac{\partial f}{\partial \operatorname{Cts}_{1}}=\frac{W F_{1} * 3.413 / \mathrm{hr}}{\mathrm{k}_{2}+\mathrm{k}_{4} / \mathrm{hr}}$

$\frac{\partial f}{\partial \operatorname{Cts}_{2}}=\frac{\mathrm{WF}_{2} * 3.413 / \mathrm{hr}}{\mathrm{k}_{2}+\mathrm{k}_{4} / \mathrm{hr}}$

$\frac{\partial f}{\partial C t s_{3}}=\frac{\mathrm{WF}_{3} * 3.413 / \mathrm{hr}}{\mathrm{k}_{2}+\mathrm{k}_{4} / \mathrm{hr}}$

$\frac{\partial f}{\partial C t s_{\text {pump,s }}}=\frac{W F_{\text {pump, s }} * 3.413 / \mathrm{hr}}{\mathrm{k}_{2}+\mathrm{k}_{4} / \mathrm{hr}}$

$\frac{\partial f}{\partial(\Delta T)}=\frac{U A}{k_{3}+k_{4} / h r}$ 
with

$$
\begin{aligned}
& k_{1}=3.12 *\left(C t s_{1} * W F_{1}+C t s_{2} * W F_{2}+C t s_{3} * W F_{3}\right), B t u / h \\
& k_{2}=U A * \Delta T, B t u / h
\end{aligned}
$$$$
k_{3}=\text { torque } * \text { speed } * \frac{63025}{2546.05}, \mathrm{Btu} / \mathrm{h}
$$$$
k_{4}=\operatorname{Cts}_{\text {pump,s }} * W F_{\text {pump,s }} * 3.413, \mathrm{Btu} / \mathrm{h}
$$$$
W F_{1}=19.50, W / \text { count } \quad W_{2}=20.00, W / \text { count }
$$$$
\mathrm{WF}_{3}=1.024 \text {, W/count } \quad W F_{\mathrm{pump}, \mathrm{s}}=.05449, \mathrm{~W} / \mathrm{count}
$$

$\mathrm{UA}=13.5, \mathrm{Btu} / \mathrm{h}^{\circ} \mathrm{F}$

The absolute errors have been taken from manufacturers' catalogues. The values are:

$$
\begin{aligned}
& \Delta C s_{1,2,3}=1 \mathrm{Ct} \\
& \Delta \operatorname{Cts}_{\mathrm{pump}, \mathrm{s}}=1 \mathrm{Ct} \\
& \Delta \text { torque }=1 \mathrm{inlb} \\
& \Delta \text { speed }=5 \mathrm{Rpm} \\
& \Delta \mathrm{hr}=1 / 36000 \mathrm{hr} \\
& \Delta(\Delta \mathrm{T}) \quad=0.5^{\circ} \mathrm{F}
\end{aligned}
$$

With these equations and the test results the values of Figure 10 have been calculated. 

1. PUELICATION OR REPORT NUMBER NISTIR 4406

2. PERFORMINO ORGANIZATION REPORT NUMBER

\section{PUBUCATION DATE}

OCTOBER 1990

\section{TITLEAND SUBTITLE}

An Initial Laboratory Evaluation of a Single Solution Circuit Cycle for Use with Nonazeotropic Refrigerants

5. AUTHOR(S)

Martin Buschmeier, William Mulroy, David Didion

6. PERFOAMING ORGANIZATION (IF JOINT OR OTHER THAN NIST, SEE INSTRUCTIONS)

U.S. DEPARTMENT OF COMMERCE

MATIONAL INSTITUTE OF STANDARDS AND TECHNOLOGY

GAITHERSBURG, MD 20899

\section{CONTRACT/GRANT NUMBER \\ 8. TYPE OF REPORT AND PERIOD COVERED}

9. SPONSORING ORGANIZATION NAME AND COMPLETE ADDRESS (STREET, CITY, STATE, ZIP)

U.S. Department of Energy

Oak Ridge National Laboratory

Oak Ridge, TN 37831-6070

10. SUPPLEMENTARY NOTES

DOCUMENT DESCRIBES A COMPUTER PROGRAM; SF-185, FIPS SOFTWARE SUMMARY, IS ATTACHED.

11. ABSTRACT (A 200-WORD OR LESS FACTUAL SUMMARY OF MOST SIGNIFICANT INFORMATION. IF DOCUMENT INCLUDES A SIGNIFICANT BIBLIOGRAPHY OA UTERATURE SURVEY, MENTION IT HERE.)

Tests were conducted at the National Institute of Standards and Technology (formerly National Bureau of Standards) to evaluate a single solution circuit cycle for use with nonazeotropic refrigerant mixtures. The single solution circuit cycle incorporates a liquid refrigerant pump in parallel with a compressor. This allows separate control of refrigerant composition to match load and of refrigerant temperature change (glide) in the two-phase region to match the heat source or sink temperature glide. Load matching by composition shifting to match light loads was found to be an inefficient air conditioning mode control strategy. Nonlinearit of enthalpy vs. temperature in the two-phase region of the tested nonazeotropic refrigerant mixture (R22/R11) limited the efficiency gains possible by glide matching to a $19 \%$ improvement over pure R22. The cycle did function as intended, allowing glide matching over a wide composition change. It is felt that with a more linear refrigerant, substantial efficiency gains over the normal vapor compression cycle would be possible for applications in which the heat source and sink glides vary substantially with load.

12. KEY WORDS (6 TO 12 ENTAIES; ALPHABETICAL ORDER; CAPITALUZE ONLY PROPER MAMES; AND SEPARATE KEY WORDS BY SEMICOLONS) air conditioning, capacity modulation, heat pumping, nonazeotropic refrigerants, refrigeration cycles, refrigerant mixtures, single solution circuit, vapor compression cycle

FOR OFFICIAL DISTRIBUTION. DO NOT RELEASE TO NATIONAL. TECHNICAL INFORMATION SERVICE (NTIS).

ORDER FROM SUPERINTENDENT OF DOCUMENTS, U.S. GOVERNMENT PRINTING OFFICE, WASHINGTON, DC 20402.

\begin{tabular}{|l|}
\hline 14. NUMBER OF PRINTED PAGES \\
46 \\
\hline 15. PRICE \\
\end{tabular}

ORDER FROM NATIONAL TECHNICAL INFORMATION SERVICE (NTIS), SPRINGFIELO, VA 22161.

\section{ELECTRONIC FORM}




